\title{
Creativity and Critique: Gap Analysis of Support for Critical Research on Big Data
}

COMPROP RESEARCH NOTE 2016.2

\author{
Philip N. Howard \\ Oxford University \\ philip.howard@oii.ox.ac.uk \\ @pnhoward
}

\author{
Samantha Shorey \\ University of Washington \\ sshorey@uw.edu \\ @.SamShorey
}

Samuel C. Woolley

University of Washington

samwooll@uw.edu

@samuelwoolley
Mengjun Guo

University of Washington

mjguo@uw.edu

@)casual_glance 


\section{CONTENTS}

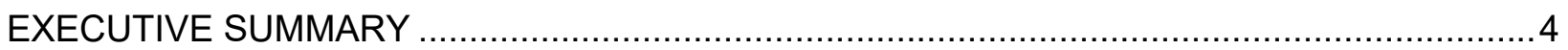

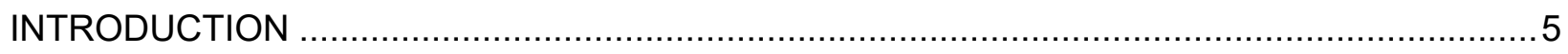

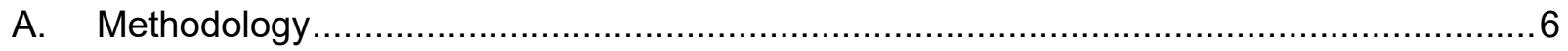

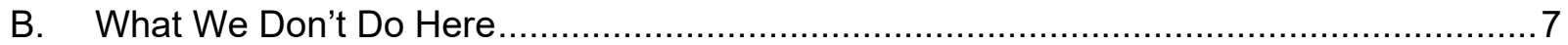

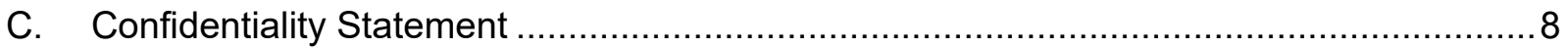

CRITICAL BIG DATA CATALOG

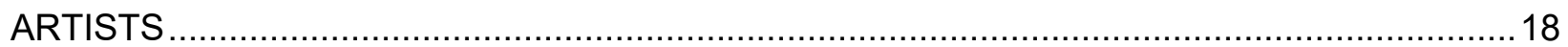

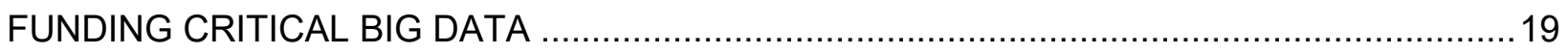

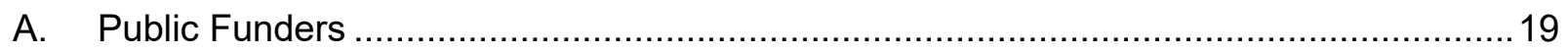

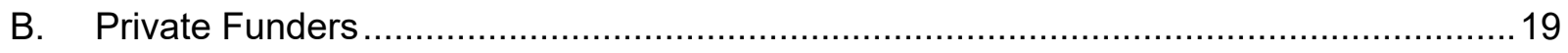

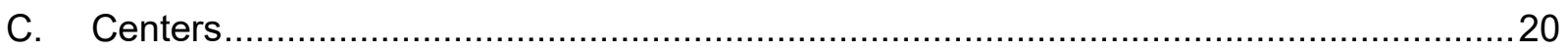

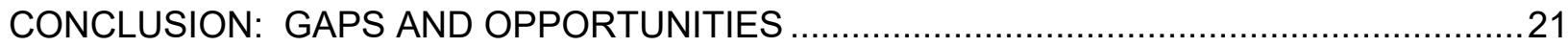

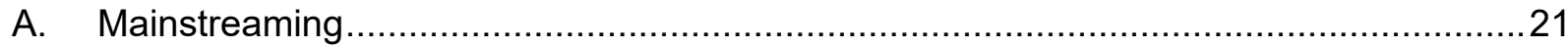

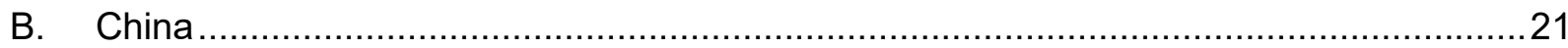

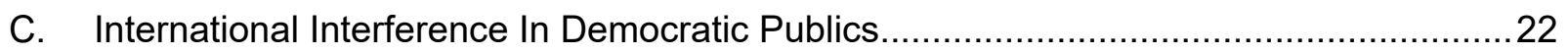

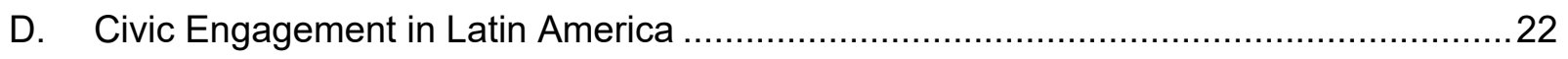

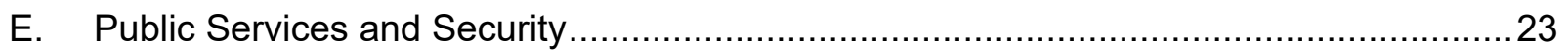

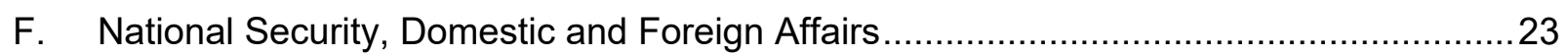

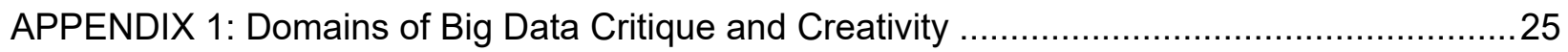

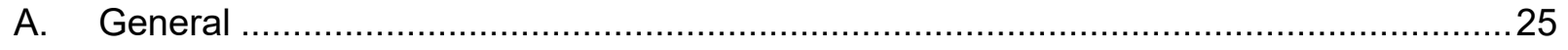

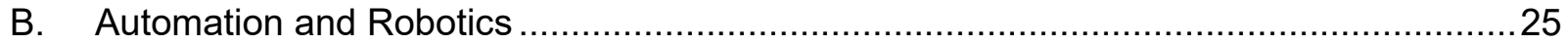

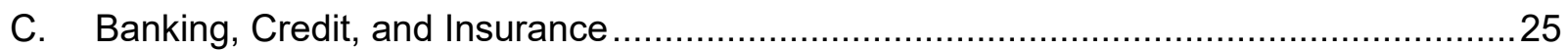

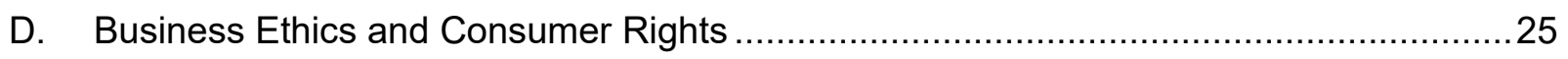

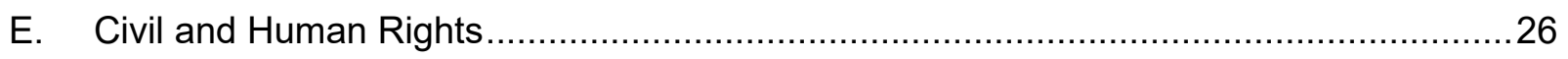

F. Democracy, Elections, and Political Communication ...............................................26

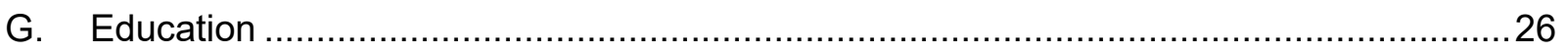

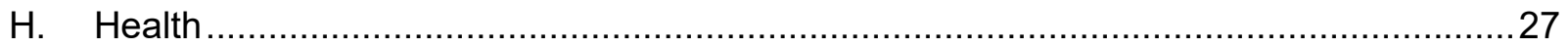

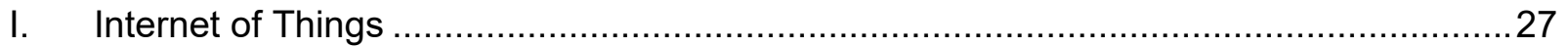

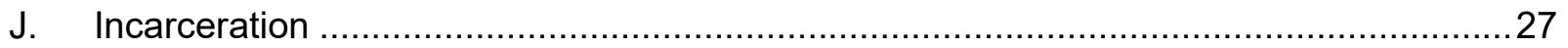

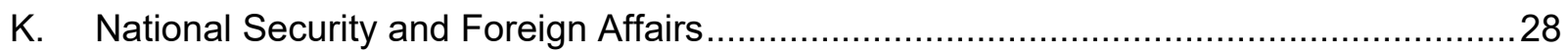

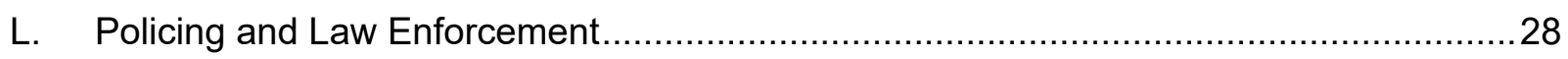




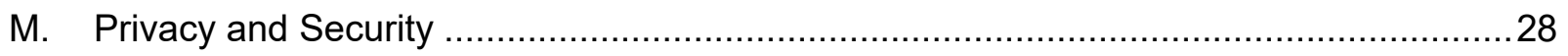

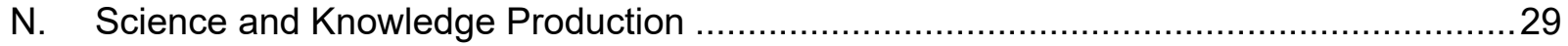

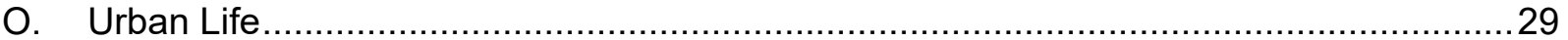

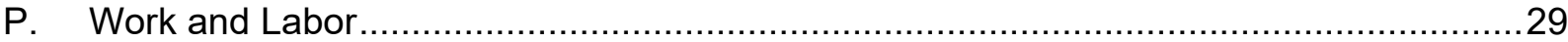

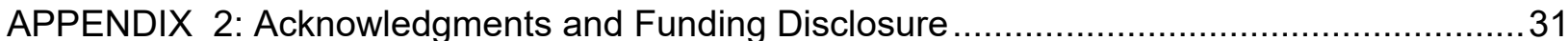

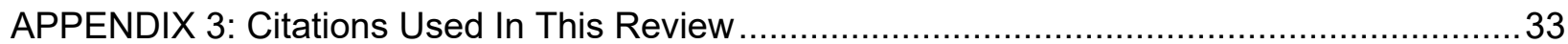

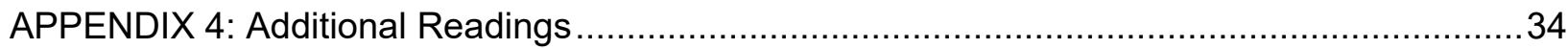




\section{EXECUTIVE SUMMARY}

- We define big data as large amounts of information, collected about many people, over multiple devices. We define critical big data research as efforts to demonstrate how flaws-ethical or methodological -in the collection and use and of big have implications for social inequality.

- There are many critical and creative big data research endeavors around the world. Here we present an annotated catalog of projects that:

0 are both critical and creative in their analysis of big data;

o have a distinct Principal Investigator (PI) or clear team; and,

0 are producing an identifiable body of public essays, original research, or civic engagement projects.

- We have catalogued these endeavors with as much descriptive information as possible, and organized projects by the domains of big data critique and creativity in which they are having an impact. We identify some 35 distinct projects, and several dozen individual researchers, artists and civic leaders, operating in 16 domains of inquiry.

- We recommend expanding critical and creative work in several domains:

o expanding work in China;

o supporting policy initiatives in Latin America's young democracies;

o expanding work on algorithmic manipulation originating in authoritarian countries;

0 identifying best practices for how public agencies in the United States should develop big data initiatives.

- We recommend that the next stage of support for these lines of inquiry is to help publicize the output of these projects, many of which are of interest to a handful of specialists but should be made accessible to policy makers, journalists, and the interested public. 


\section{INTRODUCTION}

There is growing concern about the degree to which digital media and device networks can be used as tools of social control. This concern is expressed in at least two ways. First, social and computer scientists are finding ways to catalog and demonstrate how algorithmic control can be exercised and abused. Second, civic actors are tracking how big data and algorithms can be used to make better policy recommendations, while also tracking how political elites use the tools.

Here we document the great variety of projects to detect and track algorithmic control of public opinion, civic engagement, and public life in countries around the world. More specifically, we look at how algorithmic control manifests in the creation and subsequent use of "big data." In this catalog, we define big data as large amounts of information collected about many people using many devices. In particular, Dalton and Thatcher ask (2014b):

- What historical conditions lead to the emergence of big data as a form of knowledge? (Barnes \& Wilson, 2014; Dalton, 2013)

- Who controls 'big data,' its production and its analysis? What motives and imperatives drive their work? (Thatcher, 2014)

- Who are the subjects of big data and what knowledges are they producing? (Haklay, 2013)

- How is big data actually applied in the production of spaces, places and landscapes? (Kitchin \& Dodge, 2011)

- What is to be done with big data and what other kinds of knowledges could it help produce? (Shah, 2013)

Asking critical questions about the socio-cultural implications of big data requires transdisciplinary insight generated among a variety of fields of study, practice, and understanding. Current projects with a focus on critiques of big data have homes in the academy, in policy-oriented think tanks, in commercial enterprise, and in government. It's crucial to note that inquiry into the problems of largescale information processing and valuation has its foundations in the wide array of papers, conferences, and informal groups focused on critical big data. Put another way, funded and unfunded projects investigating the problems of big data are supplemented by papers and workshops on the topic and vice versa. While this report gives primacy to critical big data projects that have support from internal and external funders, it also provides contextual information on key people and organizations discussing aspects of this subject who might not yet be affiliated with a formal project. So this approach widens understanding on the field of players currently critiquing big data even as it creates a clear view of gaps in study and funding.

The projects included in this report are generally conducted within or via funding from four types of organizations: businesses or economic research consortiums, policy-oriented think tanks, universities, and governmental institutions. For a coherent picture of current inquiry, this report categorizes the critical study of big data into several domains:

- Automation and Robotics

- Banking, Credit, and Insurance

- Business Ethics and Consumer Rights

- Civil and Human Rights

- Democracy, Elections, and Political Communication

- Education 
- Health

- Internet of Things

- Incarceration

- National Security and Foreign Affairs

- Policing and Law Enforcement

- Privacy and Security

- Science and Knowledge Production

- Urban Life

- Work and Labor

Projects, research, and writing within each domain are described via associated institutions, funders (if applicable), dates of operation or publication and people involved. The list of projects included in each domain is comprehensive-every project found, funded or not, is included. The list of papers, events, and workshops included complements the listed projects. Papers and events listed feature people or organizations working at the forefront of each domain and are either particularly compelling in terms of findings or useful in uncovering gaps in research and funding.

\section{A. Methodology}

Preparing this report has involved gathering and analyzing critical work on big data. We defined big data as large amounts of information, collected about many people, over multiple devices. We defined critical big data research as efforts to demonstrate how flaws - ethical or methodological-in the collection and use and of big have implications for social inequality.

The research team examined and included projects and reports produced by foundations (public and private), scientific organizations, think tanks, lone researchers, critical and cultural studies scholars, computer scientists, hackers and hacktivists, civil society groups, firms, government agencies, and military organizations. We searched the databases of the National Science Foundation, European Research Consortium, and grant alert services using relevant key terms. Many projects are linked up either in personnel sharing or co-authoring arrangements, and many of the people who responded to our questions about the state of the field offered leads to new people and projects.

Broadly speaking, the task of studying critical big data can be interpreted in one of two ways. One way is to track work that uses big data to engage with-and ideally solve-critical problems in civil society. For example, The Civic Tech and Data Collaborative supported by the MacArthur Foundation uses big data to improve the lives of low-income people. But work that mobilizes big data for social good, while important, was not the focus of this project.

A second way is to focus on the use of big data itself: its role in either directly harming the research subjects or indirectly harming the public through poor generalizations to larger populations. Big data studies done in this vein ask about the implications of big data, and use a lens of critique to think about the effects of this research on individual autonomy and social equity. This is where our research is focused.

Critiques of big data can also take a few different forms. Gillespie and Seaver's (2015) reading list on critical algorithm studies provides a helpful typology for understanding the different kinds of arguments used to think critically about big data. First, big data research can be criticized for removing human complexity and context. As people are reduced to numbers, we lose sight of the "hows and whys" of 
their actions in favor of quantifiable behaviors and outcomes. Research of this type can be crudely summarized as simply a critique of big data's accuracy, of how precisely it works.

Second, big data can be criticized because the methods used to create these enormous data sets are still reliant on individual information. Academics, policy workers, lawyers, and journalists regularly point out that businesses and organizations across numerous sectors continue to gather personal data, whether from a credit check or an online search, without individuals' consent. Even data that is "anonymized" can be linked back to individuals fairly easily (de Montjoye, Radaelli, Singh, \& Pentland, 2015). Critique in this area often takes the form of legal and policy responses to data gathering practices that infringe on personal autonomy. For example, big data allows for the accumulation of detailed personal profiles, enabling advertisers or political campaigns to "micro-target" based on information collected through internet browsing or purchasing habits (Auerbach, 2013). Research of this type can be summarized as a critique of privacy, focused on surveillance and one's right to control their own personally identifiable information.

Third, big data can be criticized because the methods used to analyze these data sets are embedded with values and reflect existing biases (Barocas \& Selbst, 2015). For example, the same predictive analytics that harvest data in order to better recommend products or songs can be used to select job candidates or make predictions about the likelihood that one may commit a crime based on one's social network (boyd, Levy, \& Marwick, 2014; Stroud, 2014). These practices are, at their core, exclusionary. For example, they may rely on existing categorizations such as "cultural fit" - similarity to those who are already employed by a company-which get programmed into metrics. Research of this type can be summarized as a critique of discrimination, focusing on big data's power to systematically favor groups of people.

Critical big data projects often mobilize multiple forms of critique. However, for the purposes of this project, we are especially concerned with the second and third forms: critiques of privacy and critiques of discrimination. Whether or not big data is accurate has limited bearing on how it is actually used by governments and corporations. The improper collection of personal data can lead to the creation of inaccurate user profiles that impact people's lives. Individual privacy notwithstanding, large-scale data sets are also used by knowledge brokers to draw generalized conclusions. These data sets are often imperfect, but trace data is used nevertheless to inform policy decisions, academic output, and healthcare codes.

\section{B. What We Don't Do Here}

It is important to note what we do not attempt in this gap analysis. The excitement about doing something in big data has led many universities and think tanks to announce big data initiatives to organize resources, provide a home for big data scientists, and publicly appear to be advancing big data science. Many such initiatives foster the cross-disciplinary collaboration necessary to make big data methodologies available to those working outside of fields of inquiry driven by statistical methods. But not all have a discernible critical element, and they may even fail to engage their own research teams with the implications of how this data is collected and utilized. These kinds of initiatives are excluded from the catalog.

Research initiatives that do engage critically with big data almost by definition have a dedicated program of reviewing the ethics of big data. For example, the Big Data Strategic Initiative at Cambridge University includes a specific research "theme" dedicated to three critical questions: the ethics of using personal information, access and ownership of data sets, and the impact of research outcomes. The 
initiative involves over $20 \mathrm{Pls}$, but from afar it seems to mostly connect existing research personnel and provide them access to supplementary and holdover funding.

\section{Confidentiality Statement}

All of the information presented here has been obtained via public means, whether through web content or interview. None of the information here is sensitive in nature: neither in terms of owner confidentiality nor of future funding prospects. We have not listed any projects for future funding that are yet to be solidified. In other words, no funder or PI contacted has asked that the information herein be kept private. 


\section{CRITICAL BIG DATA CATALOG}

Critical theory approaches to studying algorithms, big data, and social control can be powerful in the way they expose ideological projects and relations of control. Yet critical approaches to inquiry are also faulted for cherry picking examples, being rhetorically overly dramatic, and not allowing for safe generalizations. Originally, the process of critical theorizing was tied to creative production-critical observations were not the end in themselves. Critical theory was supposed to generate ideas for better ways of producing content or organizing people and then follow through with actually producing that content and building those organizations. So we take special care here to present examples of research endeavors that are not just generating critical theory research papers but are building new tools, playing with data in genuinely creative ways, or working toward transportable ideas that have the broad possibility of improving public life.

This section identifies the major endeavors, in alphabetical order, that a) are both critical and creative in their analysis of big data $\mathrm{b}$ ) have a distinct PI or clear team producing $\mathrm{c}$ ) have a distinct body of essays, original research, or civic engagement projects. Some of these endeavors have the support of major funders, but not all do.

\section{An Anthropological Examination of Algorithmic Recommendation System Design}

Principal Investigator: William Maurer

Principal Investigator Contact: wmmaurer@uci.edu

Funder: National Science Foundation

Budget: $\$ 25,200$

Website: http://www.nsf.gov/awardsearch/showAward?AWD ID=1323834

Description: This project uses a cultural anthropology-based approach to understanding online recommendation systems. The project is particularly concerned with looking at how algorithmic recommendations are affected by socio-cultural, economic, and legal contexts.

\section{Assessing and Using Big Data to Advance Social Science Knowledge \\ Principal Investigator: Eric Meyer \\ Principal Investigator Contact: eric.meyer@oii.ox.ac.uk \\ Funder: Alfred P. Sloan Foundation \\ Budget: $\$ 479,241$ \\ Website: http://www.oii.ox.ac.uk/research/projects/?id=98}

Description: Based at the Oxford Internet Institute, this project aimed to understand the social and scientific implications of large-scale data sets. The research took place between 2012 and 2014 and sought to track and understand how big data was being used by academics and social scientists. Though not explicitly critical at the outset, the project's findings may generate critical insight to the actual uses of big data.

\section{Big Data, Big Decisions (funded workshop)}

Principal Investigator: M. Lynne Markus

Principal Investigator Contact: mlmarkus@bentley.edu

Funder: National Science Foundation

Budget: $\$ 49,998$

Website: http://grantome.com/grant/NSF/IIS-1348929

Description: This workshop, based at Bentley University, explored how research should address social, economic and workforce implications of big data. Participants gathered to discuss 
potential negative outcomes of big data research. It gathered both academics and policy makers.

\section{Big Data and the Future of Privacy}

Principal Investigator: Marc Rotenberg, EPIC President and Executive Director

Principal Investigator Contact: rotenberg@epic.org

Funder: Individual Donors

Budget: Unknown

Website: https://epic.org/privacy/big-data/

Description: Big Data and the Future of Privacy is an aspect of the nonprofit EPIC: Electronic Privacy and Information Center. The project produces annual reports and brochures. It also engages with public policy, most recently drafting a letter that asked John Holdren, director of the Office of Science and Technology Policy under President Obama, critical questions about the use of big data in government.

\section{Center for Big Data Ethics, Law and Policy}

Principal Investigator: Donald Brown, Director of Data Science Institute

Principal Investigator Contact: deb@virginia.edu

Funder: Unknown

Budget: Unknown

Website: https://dsi.virginia.edu/center-big-data-ethics-law-and-policy

Description: This center is housed in the Data Science Institute at the University of Virginia. The institute unites 21 interdisciplinary faculties. The Center for Big Data Ethics, Law and Policy seeks to develop strategies and policies with which to address legal and ethical issues of big data. The center supports collaborative research and produces policy recommendations.

\section{The Citizenship Effects of Welfare Administration Technologies}

Principal Investigator: Virginia Eubanks

Principal Investigator Contact: veubanks@albany.edu

Funder: National Science Foundation

Budget: $\$ 105,000$

Website: http://grantome.com/grant/NSF/SES-0646342

Description: This project was focused on investigating the impact of computerization upon citizens and social welfare systems. It was conducted through fieldwork and interviews with stakeholders such as social workers and beneficiaries.

\section{Civil Rights, Big Data and Our Algorithmic Future}

Principal Investigator: David Robinson and Harlan Yu

Principal Investigator Contact: david@teamupturn.com

Funder: Ford Foundation (via Upturn) among others

Budget: $\$ 338,000$ from Ford

Website: https://bigdata.fairness.io/

Description: This report explores Big Data and its implication for social justice and civil rights issues. It explores both the opportunities and risks of big data in four areas: financial inclusion, jobs, criminal justice, and government use.

\section{Communities and Culture Network}

Principal Investigator: Helen Thornham 
Principal Investigator Contact: h.thornham@leeds.ac.uk

Funder: Arts and Humanities Research Council (UK) and University of Leeds

Budget: Unknown

Website: http://www.communitiesandculture.org/

Description: Targeted towards developing action plans and understandings of culture and community in the digital age. The UK-based project considers itself methodologically innovative, using a combination of network analysis and other digital methods. This group puts out volumes of research several times a year.

\section{Computational Propaganda and the Production/Detection of Bots}

Principal Investigator: Philip Howard

Principal Investigator Contact: pnhoward@uw.edu

Funder: National Science Foundation/European Research Council

Budget: $\$ 218,825 / \$ 2,165,707$

Website: www.politicalbots.org

Description: This research project began with a two-year NSF EAGER award targeted toward studying the production and dissemination of politicized bot accounts on social media through a three-part research process: construction of a comparative global event data set, interviews with bot makers and trackers and construction of original computational theory. The second grant was awarded to PI Howard and is directed at studying the political bots phenomenon in Europe.

\section{Council for Big Data, Ethics and Society}

Principal Investigator: danah boyd

Principal Investigator Contact: danah@datasociety.org

Funder: National Science Foundation, Information Technology Research

Budget: $\$ 299,340$

Website: http://bdes.datasociety.net/

Description: The Council for Big Data, Ethics and Society is a cross-disciplinary collaboration to address security, privacy and equity in big data initiatives. The council's primary goal is develop "frameworks" to help academics, government officials, and everyday people understand the critical issues associated with big data. Output has mostly been in the form of public-facing articles available on the council's website.

\section{Data Activism: The Politics of Big Data According to Civil Society}

Principal Investigator: Stefania Milan

Principal Investigator Contact: Tel.: +44 1179545160

Funder: European Research Council

Budget: \$2,309,605

Website: https://data-activism.net/2015/12/welcome/

Description: This ERC- funded, University of Bristol-based endeavor is geared toward understanding the politics of big data. It is particularly focused on developing understandings of how civil society understands data accumulation and use. Qualitative methods will be used: "(interviews with activists, field observations, infrastructure ethnography on software platforms") and computational methods (such as data mining in online repositories)."

\section{Data and Discrimination}

Principal Investigator: Seeta Pena Gangadharan 
Principal Investigator Contact: seeta.gangadharan@gmail.com

Funder: Open Technology Institute at New America Foundation

Budget: unknown

Website: https://www.newamerica.org/downloads/OTI-Data-an-Discrimination-FINAL-small.pdf

Description: This project, beginning with a preconference on the subject, brought together a variety of scholars to address the ways data leads to discriminatory practices. The final output was an edited collection of articles on the subject.

\section{Data and Ethics Working Group}

Principal Investigator: "At any given moment DEWG may or may not consist of: Elliott

Burns, Susana Cámara Leret, Kevin Logan, Geoff Howse, Jack James, Josep Perello, Tadeo

Sendon, Mike Thompson and Dave Young."

Principal Investigator Contact: infodewg@gmail.com

Funder: Unknown

Budget: Unknown

Website: www.dataethics.org

Description: This research group explores the ethics of data ownership and ideas related to the public interaction with data and data systems. Members are from various institutes (e.g., the Open Data Institute) and data-related businesses. Pertinent projects include \#bridget, \#Therythmoflife and \#TermsandConditions .

\section{Data, Human Rights, and Human Security}

Principal Investigator: Mark Latonero

Principal Investigator Contact: mark@datasociety.net

Funder: Data and Society Fellow

Budget: Unknown

Website: http://technologyandhumanrights.org/about-2/

Description: This is part of an ongoing project that broadly investigates the relationship between Information Communication Technologies (predominantly hardware) and human rights. They've recently published a primer "Data, Human Rights \& Human Security" that outlines security risks to individual privacy or possible governmental abuses.

Additionally, they maintain a blog engaged with surveillance and other privacy concerns.

\section{EqualFuture}

Principal Investigator: David Robinson

Principal Investigator Contact: david@teamupturn.com

Funder: Ford Foundation (via Upturn)

Budget: $\$ 338,000$ from Ford

Website: https://www.equalfuture.us/about/

Description: A website, newsletter, report generator, and policy resource for promoting "civil rights in the era of big data." Equal Future considers the way new technologies and methods are used to determine decisions in housing, lending, health, employment, and criminal justice. This funded project is led by the team at Upturn, working to expose how big data affects minority voices and the disenfranchised.

Fairness, Accountability and Transparency in Machine Learning (recurring conference)

Principal Investigator: Organized by Solon Barocas and Sorelle Friedler

Principal Investigator Contact: sbarocas@princeton.edu 
Funder: Part of Neural Information Processing Systems Conference/Foundation

Budget: Unknown

Website: http://www.fatml.org/

Description: This yearly conference, as the title suggests, focuses on fairness and transparency in machine learning. Attendees and speakers address growing concerns with the effect of machine borne decisions on arenas like healthcare, education, and policing. This conference occurs in different locations each year-in 2015 it was held in Lille, France. It brings together scholars from across the globe.

\title{
Fox Big Data Institute-Temple University \\ Principal Investigator: Zoran Obradovic \\ Principal Investigator Contact: zoran.obradovic@temple.edu \\ Funder: National Science Foundation-Secure and Trustworthy Computing Division \\ Budget: Unknown \\ Website: http://www.fox.temple.edu/cms research/research-beta/big-data-beta/about/vision-mission/ \\ Description: This center, though focusing on big data research generally, is also focused on understanding possible futures and social issues brought about by big data work. It is, for instance, hosting a workshop in 2016--Privacy in the Era of Big Data. This workshop, scheduled at Temple University for August 2016, is geared toward understanding the privacy implications of big data research.
}

From Data to Users: Providing Interpretable and Verifiable Explanations in Data Mining

Principal Investigator: Suresh Venkatasubramanian

Principal Investigator Contact: suresh@cs.utah.edu

Funder: National Science Foundation

Budget: $\$ 500,000$

Website: http://nsf.gov/awardsearch/showAward?AWD ID=1251049;

http://fairness.haverford.edu/iekyll//whoweare/

Description: This research endeavor is oriented toward building a user-centric computational framework for data mining - one focused on an algorithmic fairness and minimalization of disparate impact.

\section{GovLab's Open Data Impact Case Studies}

Principal Investigator: Stefaan Verhulst

Principal Investigator Contact: sv39@nyu.edu

Funder: Knight Foundation

Budget: $\$ 3,120,000$ (for GovLab)

Website: http://thegovlab.org/open-data-impact-case-studies/

Description: GovLab, as an organization, looks at both the positive and negative possibilities for big data usage. This project consists of a number of case studies that look at the global impact of open data in 19 countries.

\author{
International Network Observatory for Global Strategy and Big Data \\ Principal Investigator: Anno Bunnik \\ Principal Investigator Contact: Bunnika@hope@ac.uk \\ Funder: Business \\ Budget: Unknown \\ Website: http://networkobservatory.org/
}


Description: This "research consortium" seeks to help commercial partners use big data sensitively. Affiliate institutions are primarily Austrian, though the consortium is based in Liverpool. The Observatory is working on both global strategy and a professional "code of conduct" for big data ethics. They have also generated several academic publications on big data ethics.

\section{Max Planck Institute for the History of Science (multiple projects)}

Principal Investigator: Jurgen Renn

Principal Investigator Contact: renn@mpiwg-berlin.mpg.de

Funder: Max Planck Society/German Government/European Union/Other

Budget: Unknown

Website: https://www.mpiwg-berlin.mpg.de/en

Description: This institute conducts many research projects that focus on critical inquiry into big data.

Relevant projects include "the science of statistics and the politics of censusmaking" and "doing things with data." Both use multiple methods. The institute is based in Berlin, Germany, and regularly releases reports related to work.

The New Transparency: Surveillance and Social Sorting

Principal Investigator: David Lyon

Principal Investigator Contact: lyond@queensu.ca

Funder: Social Sciences and Humanities Research Council of Canada

Budget: Major Collaborative Research Grant, $\$ 1.8$ million over 7 years.

Website: http://www.sscqueens.org/projects/the-new-transparency/about

Description: Based in Canada at Queen's University, The New Transparency seeks to "make visible" the social process underlying surveillance and data collection. They seek to do so by examining the factors that contribute to the expansion of government surveillance, identifying the supporting infrastructure and institutional frameworks that support these practices.

\section{Open Data Institute (multiple projects)}

Principal Investigator: Tim Berners-Lee

Principal Investigator Contact: info@theodi.org

Funder: UK Government (Innovate UK), Omidyar Network

Budget: \$4.1m from Omidyar Network for "Data Culture"

Website: http://theodi.org/our-focus

Description: Several projects at the ODI focus on the merits and effects of open data access. Projects of interest include the Seventh Framework Programme for research and technological development (FP7) ICT Policy Support Programme (ICT PSP) from European Commission. The Open Data Monitor is also of interest as it maps open data projects and work.

\section{Privacy in the Infosphere: Developing Ethical Guidelines for Managing Big Data Research}

Principal Investigator: Jeffrey Collmann

Principal Investigator Contact: collmanj@georgetown.edu

Funder: National Science Foundation-Methods, Measure and Statistics division

Budget: $\$ 49,221$

Website: http://www.nsf.gov/awardsearch/showAward?AWD ID=1502325\&HistoricalAwards=false 
Description: This Georgetown University-based conference focused on building responsible research and ethics practices among scholars who perform big data research. It was geared toward developing a toolkit of these practices among NSF investigators.

\section{Peopling Europe: How data make a people}

Principal Investigator: Evelyn Sharon Ruppert

Principal Investigator Contact: e.ruppert@gold.ac.uk3

Funder: European Research Council

Budget: $\$ 2,004,268$

Website: http://www.gold.ac.uk/sociology/research/how-data-make-people/

Description: This project seeks to understand the ways, philosophically and theoretically, that data make people-that is how enumeration and statistics change culture and society. It is particularly focused on changes to census making and statistical regimes throughout Europe.

\section{The Programmable City}

Principal Investigator: Rob Kitchin

Principal Investigator Contact: Rob.Kitchin@nuim.ie

Funder: European Research Council

Budget: $\$ 2,516,890$

Website: http://www.maynoothuniversity.ie/progcity/

Description: This project attempts to ascertain the effects of data, especially socially oriented software, upon the modern city. Specifically, it asks how software affects life in the social, economic, and spatial spheres. This multi-method project asks how cities are translated into code and how code reshapes city life.

\section{Proteus: A Practical and Rigorous Tool for Privacy}

Principal Investigator: Ashwin Machanavajjhala

Principal Investigator Contact: ashwin@cs.duke.edu

Funder: NSF Career Award \#1253327

Budget: $\$ 384,403$

Website: http://db-gs.cs.duke.edu/projects/proteus

Description: This project, based at Duke University in North Carolina, is focused on generating a computational privacy tool to protect people from statistical data aggregation. This project develops purposive software into a toolkit for people concerned with statistical privacy.

\section{Ranking Digital Rights}

Principal Investigator: Rebecca MacKinnon

Principal Investigator Contact: info@rankingdigitalrights.org

Funder: John D. and Catherine T. MacArthur Foundation, John S. and James L. Knight Foundation (2014 Knight News Challenge), Ford Foundation, Open Society Foundations (US programs), The William and Flora Hewlett Foundation, The Shuttleworth Foundation (Flash Grant) Media Democracy Fund

Budget: \$150,000 fromMacArthur Foundation in 2015.

Website: www.rankingdigitalrights.org 
Description: This project works to rank/measure capabilities of several major ICT companies in the realm of digital rights. It takes corporations' other endeavors in social responsibility as a precedent.

Social and Ethical Aspects of Digital Identities. Towards a Value Sensitive Identity Management Principal Investigator: Irma Van Der Ploeg

Principal Investigator Contact: i.vdploeg@hszuyd.nl

Funder: European Research Council

Budget: $\$ 2,014,741$

Website: https://erc.europa.eu/social-and-ethical-aspects-digital-identities-towards-value-sensitiveidentity-management

Description: This interdisciplinary project is based in the Netherlands. It focuses specifically on the registration and management of personally identifiable information. It theorizes the concept of identity and brings this theorizing to bear on actual development in Identity Management technology. Their ultimate goal is to increase ethical acceptability of technological developments. The project output is anticipated to be academic in nature-producing three complementary PhD projects.

\section{Socialising Big Data}

Principal Investigator: Evelyn Ruppert, Department of Sociology, Goldsmiths, University of London Principal Investigator Contact: e.ruppert@gold.ac.uk

Funder: The Economic and Social Research Council

Budget: Unknown

Website: https://sloddo.wordpress.com/projects-2/socialising-big-data/

Description: A collaboration between The Center for Research on Socio-Cultural Change, The Center of Economic and Social Genomics, and "Centers for Doctoral Training" (DTCs) at three UK universities. Socialising Big Data focuses on the "new vulnerabilities" created by the generation of new "data-objects" or data sets. These vulnerabilities include ethical risks (such as privacy and security) and also risks of accuracy (representativeness and stability) that can make research vulnerable to failure. The project seeks to develop a set of concepts that can be used by industry practitioners, policy makers, and academics as they produce and use big data.

\section{Stratified Surveillance: Policing in the Age of Big Data \\ Principal Investigator: Sarah Brayne \\ Principal Investigator Contact: sarahbrayne@gmail.com \\ Funder: Horowitz Foundation for Social Policy \\ Budget: $\$ 12,500$ \\ Website: https://sites.google.com/site/sarahbrayne/}

Description: Brayne's research program focuses on the sociological implications of big data used in policing. Her research specifically focuses on the Los Angeles Police Department, studying how big data analytics affect surveillance practices and social inequality. The research output is her PhD dissertation and associated articles.

\section{Tech Policy Lab}

Principal Investigator: Ryan Calo

Principal Investigator Contact: rcalo@uw.edu

Funder: Microsoft 
Budget: Unknown

Website: http://techpolicylab.org/funding/

Description: Based at the University of Washington, The Tech Policy Lab is a multidisciplinary collaboration focused on improving technology policy especially in relation to innovative technologies. Areas of interest include robotics, the Internet of Things, and cities. They are currently looking at how big data may be translated into robotics. For example, how might robots gather data from cloud computing to operate in the world and what are the possible legal implications?

\section{WeTheProtestors}

Principal Investigator: Anonymized-see: http://www.wetheprotesters.org/about/

Principal Investigator Contact: info@wetheprotestors.org

Funder: crowd sourced donations/unknown

Budget: unknown

Website: http://www.wetheprotesters.org/

Description: This national advocacy organization is focused on equipping activists with cutting-edge tools, research, and policy solutions to end police violence in their communities. Examples of work include: MappingPoliceViolence.org, CheckthePolice.org, and ProtesterProgress.org. 


\section{ARTISTS}

While we did not explicitly set out to catalog art projects, we have noticed much productive collaboration between artists and social or computer scientists. The dramatic delivery of critique is sometimes more powerful when delivered by artists.

Because artists often produce multiple projects connected through an overarching theme, their work didn't fit easily into the format of the Critical Big Data catalog. Art is an important site of critical engagement with big data. It provides a visual and emotive connection to a numeric world that can feel abstract and isolating. Artists whose work engages critically with big data are listed below, with a brief synopsis of their body of work and titles of relevant projects.

Trevor Paglen

Paglen's work is united by a recurring theme of visibility and the US government-photographing classified military sites (Limit Telephotography), satellites (The Other Night Sky), and listing classified military terms (Code Names).

ThickEar

ThickEar is a London-born artist collective whose work is focused on the everyday personal data "transactions." A recent installation, titled Record Store, allowed people to take personalized cassette tapes in exchange for personal information. A previous installation, titled Pink Sheet Method, received funding from The Open Society Foundation.

Josh Begley

Begley is an American artist who creates art through aggregate information. For example, a recent project provided real-time and historical data about every reported US drone strike (Drone Stream). Others are collections of Google Map snapshots that show aerial views of US Prisons (Prison Map) and sites of police violence (Officer Involved).

Yanni Loukissas

Loukissas is director of Georgia Tech's Local Data Design Lab. His work studies big data as a culture form through a combination of ethnography and visualization. His most recent project, Local Data, is a book that aims to highlight the specificity, rather than generality, of data through its engagement with localdata collections (such as the real estate site, Zillow, and NewScape, UCLA's collection of two-hundred thousand local news broadcast transcripts). 


\section{FUNDING CRITICAL BIG DATA}

This section describes the programs of the most high-profile funders and programs in these domains.

\section{A. Public Funders}

The two largest public science funders of critical big data work are the National Science Foundation (NSF) and the European Research Consortium (ERC). While we have been successful in cataloguing individual projects that fit our understanding of critical big data work, it has proven much more difficult to estimate the big organization-wide or sector-wide spending patterns. At the NSF, the bulk of dedicated big data work is conducted by the Computer Science and Engineering Directorate under its "Secure and Trustworthy Computing" program, with a budget of $\$ 75$ million USD a year. This program includes initiatives to work across social and computer sciences, and other scientific programs additionally spend in this domain. The Social and Behavioral Sciences Division supports singular projects that do big data work and collaborates with other directorates, but has no dedicated program.

The ERC does not have a dedicated program on big data, but has supported several academic projects doing big data work, including Computational Propaganda (Howard), Datactive (Milan), and Responsible Authoritarianism (Stockmann). These are large awards given to individual researchers as career awards and are intended to support basic science. Other ERC programs for workshops and research networks make use of big data but tend to involve industry partners and tend not to be very critical.

On occasion the government "Privacy Commissioners" around the world support original research, either by tasking their internal research staff or by contracting out. Recently, the Privacy Commissioner of Canada released "Data Brokers: A Look at the Canadian and American Landscape". This report reviews the major "data brokers" in the US and Canada. The project is geared to understanding how these brokers are "compiling and selling individuals' personal information." They argue that the use of data for marketing or other purposes raises privacy concerns. These concerns result, in part, from "a lack of transparency and openness and the challenges individuals face in trying to exert control over their information. While Privacy Commissioners in Australia, Canada and the United Kingdom have collaborated on original research, they do not have a large or consistent program of support.

\section{B. Private Funders}

The Sloan Foundation was one of the first private funders to invest in critical data research through a project on the Oxford Internet Institute. However its significant investment in US-based data science, described below, does not have a particularly critical big data agenda. The primary funders of critical big data work include the Ford Foundation, MacArthur Foundation, Open Society Foundation, and Knight Foundation, and many of the projects detailed in the Critical Big Data Catalog and in Appendix 1 in the catalogue are supported by one or more of these primary funders.

There are two additional private funders that have made large single investments in particular critical data projects. The Adessium Foundation has several programmatic goals involving the promotion of critical inquiry through big data, primarily involving public life in Europe. Details on what it actually supports in this domain are fleeting, but it does host an annual Data Harvest conference that teaches investigative journalists about using data mining tools. The Omidyar Network has recently committed $\$ 4.1 \mathrm{~m}$ to the Open Data Institute, and while open data initiatives have become an important feature of modern democracies, very few open data initiatives have a strong reputation for critical big data policy analysis. Much of that work falls to other non-governmental organizations, who nonetheless depend on data being open. 


\section{Centers}

There are only a handful of "centers of excellence" on critical big data. We define a critical big data research center as an independent organization with multiple staff, multiple funders, and a credible reputation for both supporting original research and disseminating the findings of such research. There are two with a strong record, and two centers to watch. The two existing organizations with the most coherent programs on big data are Data \& Society and the Oxford Internet Institute. The first supports many kinds of individual researchers, builders, and public writers. It has a strong reputation for critical inquiry and a demonstrated ability to place opinion writing and commentary essays about the use of big data. The second is a home for several different kinds of critical big data projects. It offers training programs and content to academics, policy makers, and civic groups.

Centers to watch include the new Alan Turing Institute, a UK-based organization that involves government, industry, and academic partners. It has expressed an interest in the policy and ethics of big data, but as a new organization it has little record of discovery. In this domain. The Moore-Sloan Data Science Environments program has seeded several research universities in the US. It has a budget of $\$ 38$ million USD across several campuses. While this program seeks to support the social and critical aspects of big data research, most of the investment benefits the hard sciences and these centers have yet to demonstrate leadership in critical inquiry. 


\section{CONCLUSION: GAPS AND OPPORTUNITIES}

In this section, we identify areas where research could have a real-world impact on shaping policy, social norms, or public norms by cultivating critical big data work. While the amount of attention to critical big data work is growing, there is also lots of opportunity for new lines of creativity and critique. Just as important, we argue that the existing lines of inquiry need to be "mainstreamed."

\section{A. Mainstreaming}

A significant amount of the critical big data work occurs in small teams or with individual researchers who publish in academic journals. The next big step for the broad project of improving our understanding of the political power of algorithms is to get the traditional think tanks, political players, public policy makers, journalists, and the interested public to raise their sophistication with the technical and political issues involved. A way to do this is to "mainstream" the issue by prompting organizations to develop their own in-house research staff, their own small granting efforts, and their own policy competence. Supporting existing organizations (such as the US Institutes of Peace, the National Endowment for Democracy, or the Center for Responsive Politics) through financing and program development advice would allow more mainstream organizations to start working on critical big data. By mainstreaming we mean:

a) improving the sophistication of journalists working with big data or writing on it;

b) raising the literacy of public policy makers on the findings of critical research; and

c) ultimately drawing popular attention to the impact of algorithms on public life.

Although many of the projects we identified in our catalog are multidisciplinary, there is a lack of research that collaborates across sectors. Research that incorporates individuals situated in businesses, governments, and the academy will foster a more nuanced understanding of the ways in which big data is used, and the mechanisms that may (or may not) be in place to make sure it is used acceptably. It will allow for researchers to arrive at critiques and solutions that take into account the actual practices and constraints of institutions that utilize big data-rather than merely critiquing from ethical ideals. Some of the most rigorous thinking about big data is being done by isolated critical theorists, whose powerful ideas aren't being integrated into work done by other academics (social scientists, computational scientists) much less those who are building systems or writing policy. Critical big data research needs teams of researchers to build conceptual bridges and identify shared terms, so that the work being done across paradigms, fields, and sectors can be maximally effective.

What is important to the people who make and implement systems that utilize big data? What tradeoffs occur in the considerations of ethical data practices and how can these trade-offs be made visible? If critical inquiry on big data exposes opportunities and flaws, what is the best route to publicizing findings and giving policy makers actionable evidence? How can we raise the amount and quality of news coverage on algorithmic control? What can we teach civil society groups that are not focused on technology issues about the importance of critical big data work for their own activities?

The two widely recognized centers of excellence for critical big data work, Data \& Society and the Oxford Internet Institute, tend to capture the attention of policy makers and journalists, and have been particularly good outlets for mainstreaming critical big data findings.

\section{B. China}

Our current understanding of algorithms and social control in China is extremely limited. We know that the vast majority of Chinese citizens use a relatively narrow suite of tools that duplicate the technology 
services and applications offered in other countries. Yet we also know that these tools are built by state agencies with censorship and surveillance as a core design value. Nonetheless, we know little of how algorithmic manipulation occurs over systems like Weibo, Renren, and WeChat. China is important for multiple reasons. First, on the question of algorithms and social control, China's information infrastructure will shape the lives of a billion people. Second, China is the source of algorithmic manipulations-such as social media "bots" - that have an impact on public life in democracies. Third, many of the hardware and software innovations by the Chinese state are being sold to other countries hoping to develop their information infrastructure. This means that the tools for algorithmic control are being exported to other authoritarian regimes that also seek an internet for social control, while Chinese security services retain ultimate control.

What are the specific structures and functions of algorithmic control and big data manipulation in China? How do citizens-and democracy advocates-respond or circumvent and how widespread is critical knowledge of algorithmic control? What are the mechanisms by which the Chinese government uses big data to influence social media and public opinion beyond its borders?

In particular, Silvia Lindtner at the University of Michigan studies makerspaces in China and has an active lab of junior scholars working on critical big data research in that country. Danie Stockmann at Leiden University has also researched the use of big data in Chinese Media and is an expert on political authoritarianism.

\section{International Interference In Democratic Publics}

A growing number of authoritarian regimes are using algorithms to manipulate not only conversations in their own countries but the public spheres of democracies. Strategies include attacking civil society groups in democracies, muddying international debate on sensitive security issues, and interfering with public opinion during elections.

Which countries try to exercise "soft power" through algorithms and big data? How often, and in what ways, do governments meddle in the public sphere of other countries using big data and algorithms? How is political discourse and good governance in democracies and open societies threatened by algorithmic manipulation originating outside their borders?

\section{Civic Engagement in Latin America}

There are several countries in Latin America where big data and the internet of things actually represent opportunities for civic engagement. Global attention may be focused on political crises and recalcitrant regimes across Asia, Eastern Europe, and the Middle East, but it is in Latin America that we find relatively stable democracies with political interest in investing in public information infrastructure. There are also some fairly specific opportunities to engage with Latin American civil society groups on the horizon. Chile will be rewriting its Constitution in the next two years, and has signaled interest in crowdsourcing the constitutional process, in addressing privacy issues at the constitutional level, and in investing in e-voting. Cuba is a country with relatively high levels of engineering education that is opening and transitioning. Argentina is home to an active community of hacktivists. Brazil has a unique history of technology-enabled participatory budgeting, an exceptionally vibrant social media user population, a commitment to open source software, a sophisticated level of public interest in a "Marco Civil," and broad values of technology use that differ from those in the United States. If there is a region where making the analysis and findings of critical big data work will be welcomed and translated into policy action, that region is Latin America. 
In particular, the Chilean think tank Fundacion Democracia y Desarrollo is run by a popular ex-president who is spearheading the crowdsourcing of constitutional reforms but is too old to run for office himself. The organization has a "Social Lab for Civic Engagement" that brings together some of the country's political, corporate, and civic leaders for conversations about technology and political participation.

\section{E. Public Services and Security}

A growing number of public services, including policing, are being caught up in an uncritical drive for big data analysis. There are many kinds of models for making various levels of government more sophisticated in their use of data, but some models must be better than others. One business model (Palantir) is to crowdsource data gathering using publicly accessible records, but then sell real-time data back to municipal governments in Los Angeles after processing the data through proprietary algorithms. The City of Chicago collects vast amounts of information ostensibly through policing operations, but releases some of the data through an open data initiative that helps local entrepreneurs develop hyper local apps. It is not known how much policy oversight there is or ethical review there has been of such efforts to bring data into city government. A study of best practices or a recommended process for "data-flying" cities, perhaps in conjunction with the national conference of mayors, would help set a high standard for transparent and ethical big data involving public housing, policing, and other public services.

How should public agencies engage with private data vendors when exploring new big data projects? What kind of big data training should contemporary policy makers have? When should big data projects and data be developed within public agencies, and when should they be contracted out (and under what terms)?

In particular, sociologists Alison Powell (LSE) and Sarah Brayne (University of Texas) study cities, dataficataion and social inequality.

\section{F. National Security, Domestic and Foreign Affairs}

The work of Edward Snowden and Julian Assange brought to light a profusion of new ways in which data, computation, and advanced technology have/are used in intelligence operations domestically and abroad. These revelations were centered on the idea that new varieties of surveillance were invading the privacy of citizens. Essentially, security practitioners were accused of building massive databases of information containing all sorts of communication-with little attention to nuance or relevance. Because concerns stemming from these various leaks center on more acute questions of surveillance and privacy, the role of big data, and its continued application in national and international security settings, is often obscured or supplanted by generalized conversation. More robust conversation about the way big data research affects both domestic and foreign policy is certainly needed. Although the use of big data by corporations has received increasing critical attention, more research is needed on how this information is collected and used by institutions and governments.

How much data collection is too much? What kind of public policy oversight would allow national security agencies to meet reasonable collection goals?

The Electronic Freedom Forum, Center for Democracy and Technology, Privacy International and Global Networking Initiative are among the best non-governmental organizations for tracking these issues and answering these questions. Their normative agenda is not unpalatable, and while they do not have a strong record for doing comprehensive and critical big data analysis, they are organizationally stable enough that they could do some creative work in this domain. 
Critical data research is flourishing but needs help turning insights into creative applications. It has proven relatively straightforward (though not easy) to audit algorithms, find fault in the political economy of data, identify the research and policy projects with questionable ethics, and demonstrate the inadequacies of social research that is not self-reflexive. 


\section{APPENDIX 1: Domains of Big Data Critique and Creativity}

\section{A. General}

1. Description: This domain of inquiry can be viewed as an 'umbrella' conversation about critiques of big data. Rather than examining a particular arena in which big data research has equally particular effects, general inquiry seeks to highlight the wide-ranging problematic associated with reliance on numbered solutions to human problems. This domain is centered on a question such as "What are the social and cultural ramifications of communicating and enacting generalizations drawn from large data sets?"

2. Exemplary Projects

3. Example Research, Writing, or Other Output

a. OTI at New America's Data and Discrimination book

b. Big data's disparate impact by Barocas and Selbst

c. Critical Questions for Big Data by boyd and Crawford

d. Gary Marcus, The New Yorker (online), April 3, 2013.

\section{B. Automation and Robotics}

1. Description: Robotics complicates concepts of big data because robots can be designed to download and execute actions via cloud-based data. Access to large swaths of data could prove useful for robots run by self-learning software, but automated use of such data could also lead to unexpected or dangerous behavior of technologies such as drones, driverless cars, or medical robotics.

2. Exemplary Projects
a. Tech Policy Lab at UW

3. Example Research, Writing, or Other Output

a. Ryan Calo, Robotics and Lessons of Cyber Law

b. R.T. Ford, Save the Robots: Cyber Profiling and Your So-Called Life

c. Nick Bilton, Friends, and Influence, for Sale Online http://bits.blogs.nytimes.com/2014/04/20/friends-and-influence-for-sale-online/

d. Yazam Boshmaf et al, The Socialbot Network: When Bots Socialize for Fame and Money

\section{Banking, Credit, and Insurance}

1. Description: Modern banking is driven by complex data-driven algorithmic trading-often automated without close oversight from humans. Data collection by credit and insurance brokers presents an early example of data-driven discrimination. Ford [2000] flags the practice and potential future harms of basing credit availability on dehumanized data throughout the late 90 s.

2. Exemplary Projects: Social and Ethical Aspects of Digital Identities. Towards a Value Sensitive Identity Management.

3. Example Research, Writing, or Other Output

a. Yian Q. Mui, Little-known firms tracking data used in credit scores Washington Post, July 16, 2011.

b. Tim Harford, Big Data: Are We Making a Big Mistake, Financial Times, March 28, 2014.

c. Katherine Noyes, Will Big Data Help End Discrimination--or Make it Worse?, Fortune.

\section{Business Ethics and Consumer Rights}

1. Description: Projects concerned with the relationship of big data, business ethics, and consumer rights seek to understand how responsibly businesses handle and store data, but also whether businesses are selling data for profit. 
2. Exemplary Projects: Ranking Digital Rights, The Tradeoff Fallacy: How Marketers Are Misrepresenting American Consumers and Opening Them Up to Exploitation

3. Example Research, Writing, or Other Output

a. Work of Joseph Turow at UPenn Annenberg

b. Landscaping of data brokers Office of the Privacy Commissioner of Canada

c. Nathan Newman, Google, Ebay, Amazon, and Yahoo! Team Up to Gut Consumer and Privacy Laws, Data Justice block, April 27, 2015.

\section{E. Civil and Human Rights}

1. Description: This area of inquiry, related to the ways big data is used or misused in policing, politics, health, and a variety of other arenas, explores how big data might be harnessed in violation of civil or human rights. Several related projects document the rise of data-driven discrimination-wherein social decisions derived via big data analysis lead to unfair treatment of minorities.

2. Exemplary Projects: Data and Discrimination from the Open Technology Institute at the New America Foundation

3. EqualFuture/Civil Rights, Big Data and Our Algorithmic Future

a. "Data, Human Rights \& Human Security" @ Technology \& Human Rights

b. Center for Big Data Ethics, Law and Policy

4. Example Research, Writing, or Other Output

a. Frank Pasquale, The Black Box Society

b. Mining mobile youth cultures

c. Latanya Sweeney, Discrimination in Online Ad Delivery, ACM Queue, 11:3 10-28, 2013.

d. Room for Debate, Is Big Data Spreading Inequality? NY Times, August 6, 2014.

\section{F. Democracy, Elections, and Political Communication}

1. Description: Data-driven polls, socially automated actors (bots), campaign protocols, etc. are of concern to those focused on the critical study of big data in politics. Political campaigns in Western democracies now operate via data-focused systems for voter outreach and categorization, self-learning social bots attack activists and spread propaganda worldwideresearchers in this field attempt to understand the effects of big data in situations such as these.

2. Exemplary Projects

a. Computational Propaganda: www.politicalbots.org

3. Example Research, Writing, or Other Output

a. Big Data: Seizing Opportunities, Preserving Values, Executive Office of the President, May 2014.

b. Zeynep Tufekci, Engineering the Public

c. Robert Epstein, How Google Could Rig the 2016 Election Politico Magazine August 19, 2015.

a. Micah Sifry, Facebook Wants You to Vote on Tuesday. Here's How It Messed With Your Feed in 2012. Mother Jones, October 31, 2014.

\section{G. Education}

1. Description: Big data is used in educational settings for student placement, testing, aptitude evaluation (for states, regions, districts and students), and a variety of other sub-areas. Critical researchers of these practices study outcomes and effects of these data-reliant education systems but also attempt to understand potential positive futures for the use of big data in school systems.

2. Exemplary Projects 
a. Assessing and Using Big Data to Advance Social Science Knowledge @ Oii

3. Example Research, Writing, or Other Output

a. Carol Burris, Principal uncovers flawed data in her state's official education reports Washington Post, Nov. 22, 2014.

b. Farai Chideya, No Child Left Un-mined? Student Privacy at Risk in the Age of Big Data The Intercept, June 27, 2015.

c. Cathy O'Neil, Value-added model doesn't find bad teachers, causes administrators to cheat "mathbabe" blog, March 31, 2013.

\section{H. Health}

1. Description: Research concerned with big data used in healthcare has grown at pace with the industry's switch from paper to digital records. The massive amount of healthcare data in the world leaves pundits concerned with leaks or discriminatory outcomes. What's more, scientists and companies now often use big data in attempts to predict disease outbreaks and healthcare crises.

2. Exemplary Projects: The Citizenship Effects of Welfare Administration Technologies

3. Example Research

a. The work of Gina Neff and Brittany Fiore-Gartland

b. David Lazer et al, Google Flu Trends Still Appears Sick: An Evaluation of the 2013-2014 Flu Season

c. Declan Butler, When Google got flu wrong, Nature

d. Kaiser Fung, Google Flu Trends Failure Shows Good Data > Big Data, Harvard Business Review Blog, March 25, 2014.

\section{Internet of Things}

1. Description: The internet of things (IOT) refers to the multitude of physical devices, automobiles, climate control systems, appliances, etc., that are connected to the internet and thus swaths of data. Critical research making a study of the loT looks at the ways information gathered from these device systems are used in ways unexpected by owners or operators. Scholars, pundits, and professionals concerned with a globally connected physical world make security and privacy key arenas of focus.

2. Exemplary Projects

a. IoT Privacy Forum and founder Gilad Rasner

3. Example Research, Writing, or Other Output

a. Bessis and Dobre, Big Data and the Internet of Things

b. Phil Howard, Pax Technica

c. Greengard, The Internet of Things

\section{J. Incarceration}

1. Description: Data analysis techniques using big information streams is now essential in many states' considerations of sentencing, parole, and other aspects of incarceration. A growing field now makes the use of big data in prison systems its focus because so-called "riskassessment" software makes computational decisions about lives of incarcerated citizens. Additionally, sensitive information about prisoners' backgrounds is stored online-leading to questions about security and privacy of said data.

2. Exemplary Projects: EqualFuture, Civil Rights, Big Data and Our Algorithmic Future

3. Example Research, Writing, or Other Output

a. Massimo Calabresi, Attorney General Eric Holder to Oppose Data-Driven Sentencing, Time Magazine, July 31, 2014

b. Luis Daniel, The dangers of evidence-based sentencing mathbabe blog guest post, October 21, 2014. 
c. Sonja Starr, Sentencing by the Numbers New York Times Op-Ed, August 10, 2014.

d. Eileen Sullivan and Ronnie Greene, States predict inmates' future crimes with secretive surveys, AP, February 24, 2015.

\section{K. National Security and Foreign Affairs}

1. Description: The Snowden revelations made it clear that intelligence services in many countries, particularly in the US and UK, build and use large data sets in spying missions and among many sectors of domestic and foreign affairs. Those that criticize this practice often do so under the banner of privacy, meaning that big data's role in security practices is often clouded or misinterpreted. There has been a large amount of work done on governmental practices surrounding the actions of Snowden, Wikileaks, and others. It is crucial, however, that researchers begin to better contextualize the role of data in these practices.

2. Exemplary Projects

a. USIP PeaceTech Lab, Center for Data Ethics

3. Example Research, Writing, or Other Output
a. UNICRI Big Data Report
b. Howard, Pax Technica
c. DeLong, National Security Implications of Big Data Surveillance

\section{Policing and Law Enforcement}

1. Description: There has been a recent surge of interest, especially among academics and media practitioners, about the ways law enforcement agencies use data-driven analytics to inform decisions related to policing. It has come to light that the New York Police Department, the Chicago Police Department, and agencies in over 60 other US cities use conclusions drawn from big data for predictive policing. In other words, they use computational power to predict crimes. This tactic raises many questions related to discriminatory profiling, surveillance, and police abuse.

2. Exemplary Projects

3. Example Research, Writing, or Other Output

a. Virginia Eubanks, The Policy Machine: The dangers of letting algorithms make decisions in law enforcement, welfare, and child protection. Slate, April 30, 2015.

b. Rose Hackman, Is online surveillance of black teenagers the new stop-and-frisk?

c. Matt Stroud, The minority report: Chicago's new police computer predicts crimes, but is it racist? The Verge, Feb. 19, 2014.

d. Janet Vertesi, My experiment opting out of Big Data made me look like a criminal, Time Magazine, May 1, 2014.

\section{Privacy and Security}

1. Description: Privacy and security are among the most pressing concerns of those studying issues of big data. Massive data bases of private information are vulnerable to attack and theft, and the amalgamation of other data online can pose widespread risks to security at a variety of levels. Many researchers exploring security and privacy implications of big data seek to understand and illuminate the ways big data not only challenges these ideals but also changes them.

2. Exemplary Projects

a. Social and ethical aspects of digital identities; towards a value sensitive identity management

b. The New Transparency: Surveillance and Social Sorting

3. Example Research, Writing, or Other Output

a. Sarah Brayne, Stratified Surveillance: Policing in the Age of Big Data

b. Virginia Eubanks, Digital Dead End 
c. David Auerbach, You Are What You Click: On Microtargeting

d. Adam Chandler, The Many Reasons to Dislike Facebook's Mood Manipulation Experiment. The Wire, June 28, 2014

\section{N. Science and Knowledge Production}

1. Description: The use of big data based methodology in academic settings, among STEM fields and social sciences, is widespread. Many academics use computational big data analysis to make generalized claims about the social world. This practice generates farreaching knowledge and policy. Those critiquing this practice work to build comprehension of such methods and often criticize data-driven work as dehumanizing and potentially harmful to certain populations.

2. Exemplary Projects

a. Socialising Big Data at ESRC

b. GovLab's "Data Collaboratives"

3. Example Research, Writing, or Other Output

a. Bruce Alberts, "Impact Factor Distortions"

b. James Faghmous and Vipin Kumar, A Big Data Guide to Understanding Climate Change: The Case for Theory-Guided Data Science Big Data, September 2014.

c. L. Sweeney, A. Abu, J. Winn, Identifying Participants in the Personal Genome Project by Name SSRN 2013.

O. Urban Life

1. Description: This area of inquiry, connected to the study of the internet of things, explores the way data and computation affect life in everyday settings within cities. Research projects focused on this arena map the ways code and data are used in cityscapes for a variety of purposes and critique potential power imbalances, discriminatory practices, and other socio-cultural outcomes of data-supported cities.

2. Exemplary Projects: The Programmable City, Communities and Culture Network

3. Example Research, Writing, or Other Output

a. Mike Boehm, Google's wrong information about MOCA misleads museum-goers, Los Angeles Times, Dec. 14, 2015.

b. Zeynep Tufekci and Brayden King, We Can't Trust Uber, New York Times, Dec. 8, 2014.

\section{P. Work and Labor}

1. Description: Algorithms and data increasingly serve the function that "middle-management" once did, assigning and reviewing tasks for workers. In the case of Uber, for example, an algorithm assigns drivers to passengers partially based on location-and passengers then rate drivers to ensure quality through data collection (Lee, Kusbit, Metsky, \& Dabbish, 2015). Along with these developments come a host of ethical quandaries. Geolocation puts workers under constant surveillance, allowing employers to know their whereabouts at all times in order to maximize productivity. Ratings systems favor consumers, often having no corrective measure should a worker be given a rating unfairly. And the activities of workers (and consumers) generates valuable, uncompensated, and often personally identifiable data in order to improve algorithmic systems.

2. Exemplary Projects

3. Example Research, Writing, or Other Output

a. Cathy O'Neil, Workplace Personality Tests: a Cynical View, mathbabe blog, April 16, 2015.

b. Alex Rosenblat, Tamara Kleese, and danah boyd, Networked Employment Discrimination, Data \& Society Working paper, October 2014. 
c. Sarah O'Connor, Wearables at work: the new frontier of employee surveillance Financial Times, June 8, 2015

d. Don Peck, They're Watching You at Work. ,Atlantic Monthly, November 20, 2013. 


\section{APPENDIX 2: Acknowledgments and Funding Disclosure}

For advising on this project we are grateful to:

- Nancy Baym, Principal Researcher, Microsoft Research New England

- Laura Brandimarte, Department of Management Information Systems, University of Arizona

- Finn Brunton, Department of Media, Culture and Communication, New York University

- Alberto Cerda, Ford Foundation

- John Cheney-Lippold, Department of American Culture, University of Michigan

- Kate Crawford, Principal Researcher, Microsoft Research New York City

- Greg Elmer, Department of Media, Culture and Communication, Ryerson University

- Jeremy Epstein, Secure and Trustworthy Cyberspace Program, National Science Foundation

- Brittany Fiore-Gartland, eScience Institute, University of Washington

- Tarleton Gillespie, Principal Researcher, Microsoft Research New England

- Lance Hoffman, Cyber Security Policy and Research Institute, Department of Computer Science, George Washington University

- Paul Jacobs, European Research Council

- Nathan Jurgenson, Department of Sociology, University of Maryland

- Karen Levy, Assistant Professor, Data and Society Research Institute

- Lori McGlinchey, Ford Foundation

- Eric Meyer, Oxford Internet Institute

- Anita Nikolich, National Science Foundation

- Cathy O'Neil, Mathbabe

- Eric Sears, MacArthur Foundation

- David Robinson, Upturn

- Samuel Sinyangwe, Founder, WeTheProtestors

- Stefaan Verhulst, The GovLab, New York University

- Janet Vertesi, Department of Sociology, Princeton

- Taha Yasseri, Oxford Internet Institute

- Harlan Yu, Upturn

In addition there were several advisors who wish to remain anonymous.

We gratefully acknowledge the support of several organizations, including Open Society Foundation, the Department of Communication at the University of Washington, and the Oxford Internet Institute at Oxford University. Financial support for this work was provided by the Open Society Foundation. Additional support was provided by the National Science Foundation under grant BIGDATA-145-0193 "Computational Propaganda and the Production/Detection of Bots" and the European Research Consortium under grant "COMPROP-Computational Propaganda: Investigating the Impact of Algorithms and Bots on Political Discourse in Europe." Any opinions, findings, conclusions or recommendations expressed in this material are those of the authors and do not necessarily reflect the views of the Open Society Foundation, National Science Foundation, or European Research Consortium.

\section{Citation and License}

Howard, Philip N., Samantha Shorey, Samuel C. Woolley, and Mengjun Guo. 2016. "Creativity and Critique: Gap Analysis of Support for Critical Research on Big Data." Working Paper 2016.2. Oxford, UK: 
Project on Computational Propaganda. www. politicalbots.org. This work is licensed under a Creative Commons Attribution - Non Commercial - Share Alike 4.0 International License. 


\section{APPENDIX 3: Citations Used In This Review}

Auerbach, D. (2013, February 13). You are what you click: On microtargeting. Retrieved October 13, 2015, from http://www.thenation.com/article/you-are-what-you-click-microtargeting/

Barnes, T. J., \& Wilson, M. W. (2014). Big Data, social physics, and spatial analysis: The early years. Big Data \& Society, 1(1). http://doi.org/10.1177/2053951714535365

Barocas, S., \& Selbst, A. D. (2015). Big data's disparate impact (SSRN Scholarly Paper No. ID 2477899). Rochester, NY: Social Science Research Network. Retrieved from http://papers.ssrn.com/abstract=2477899

boyd, danah, Levy, K., \& Marwick, A. (2014). The networked nature of algorithmic discrimination. In S. P. Gangadharan, V. Eubanks, \& S. Barocas (Eds.), Data and discrimination: Collected essays. Washington D.C.: Open Technology Institute and The New America Foundation.

Dalton, C. M. (2013). Sovereigns, spooks, and hackers: An early history of google geo services and map mashups. Cartographica, 48(4), 261-274.

De Montjoye, Y.-A. de, Radaelli, L., Singh, V. K., \& Pentland, A. "Sandy." (2015). Unique in the shopping mall: On the reidentifiability of credit card metadata. Science, 347(6221), 536-539. http://doi.org/10.1126/science.1256297

Gillespie, T., \& Seaver, N. (2015, November 9). Critical algorithm studies: A reading list [Research Blog]. Retrieved from http://socialmediacollective.org/reading-lists/critical-algorithm-studies/

Haklay, M. (Muki). (2013). Neogeography and the delusion of democratization. Environment and Planning A, 45(1), 55-69.

Kitchin, R., \& Dodge, M. (2011). Code/space: Software and everyday life. Cambridge, MA: MIT Press.

Lee, M. K., Kusbit, D., Metsky, E., \& Dabbish, L. (2015). Working with machines: The impact of algorithmic and data-driven management on human workers. In Proceedings of the 33rd Annual ACM Conference on Human Factors in Computing Systems (pp. 1603-1612). New York, NY, USA: ACM. http://doi.org/10.1145/2702123.2702548

Shah, V. (2013, August 28). Map of Stop and Frisks in NYC in New York City Show Concentration by Race and Neighborhood | Untapped Cities. Retrieved November 10, 2015, from http://untappedcities.com/2013/08/28/new-map-shows-police-stop-and-frisks-according-torace-and-neighbourhood-in-new-york-city/

Stroud, M. (2014, February 19). The minority report: Chicago's new police computer predicts crimes, but is it racist? Retrieved October 14, 2015, from http://www.theverge.com/2014/2/19/5419854/the-minority-report-this-computer-predictscrime-but-is-it-racist

Thatcher, J. (2014). Big data, big questions | living on fumes: Digital footprints, data fumes, and the limitations of spatial big data. International Journal of Communication, 8(0), 19. 


\section{APPENDIX 4: Additional Readings}

Amoore, L. (2009). Algorithmic war: Everyday geographies of the war on terror. Antipode, 41(1), 49-69. http://doi.org/10.1111/j.1467-8330.2008.00655.x

Ananny, M. (2011, April 14). The curious connection between apps for gay men and sex offenders. The Atlantic. Retrieved from http://www.theatlantic.com/technology/archive/2011/04/the-curiousconnection-between-apps-for-gay-men-and-sex-offenders/237340/

Ananny, M., \& Crawford, K. (2014). A liminal press: Situating news app designers within a field of networked news production (SSRN Scholarly Paper No. ID 2448736). Rochester, NY: Social Science Research Network. Retrieved from http://papers.ssrn.com/abstract=2448736

Anderson, C. (2008, June 23). The end of theory: the data deluge makes the scientific method obsolete. WIRED. Retrieved from http://www.wired.com/2008/06/pb-theory/

Anderson, C. W. (2011). Deliberative, agonistic, and algorithmic audiences: Journalism's vision of its public in an age of audience transparency. International Journal of Communication, 5(0), 19.

Anderson, C. W. (2013). Towards a sociology of computational and algorithmic journalism. New Media \& Society, 15(7), 1005-1021. http://doi.org/10.1177/1461444812465137

Aneesh, A. (2009). Global labor: Algocratic modes of organization*. Sociological Theory, 27(4), 347-370. http://doi.org/10.1111/j.1467-9558.2009.01352.x

Baker, P., \& Potts, A. (2013). "Why do white people have thin lips?" Google and the perpetuation of stereotypes via auto-complete search forms. Critical Discourse Studies, 10(2), 187-204. http://doi.org/10.1080/17405904.2012.744320

Barnes, T. J., \& Wilson, M. W. (2014). Big Data, social physics, and spatial analysis: The early years. Big Data \& Society, 1(1). http://doi.org/10.1177/2053951714535365

Barocas, S., Hood, S., \& Ziewitz, M. (2013). Governing algorithms: A provocation piece (SSRN Scholarly Paper No. ID 2245322). Rochester, NY: Social Science Research Network. Retrieved from http://papers.ssrn.com/abstract=2245322

Barocas, S., \& Selbst, A. D. (2015). Big data's disparate impact (SSRN Scholarly Paper No. ID 2477899). Rochester, NY: Social Science Research Network. Retrieved from http://papers.ssrn.com/abstract=2477899

Beer, D. (2009). Power through the algorithm? Participatory web cultures and the technological unconscious. New Media \& Society, 11(6), 985-1002. http://doi.org/10.1177/1461444809336551

Benjamin, S. (2013). Algorithms and speech. University of Pennsylvania Law Review, 161(6), 1445-1493.

Benthall, S. (2015). Designing networked publics for communicative action. Interface, 1(1). http://doi.org/http://dx.doi.org/10.7710/2373-4914.1003

Berg, M. (2014). Participatory trouble: Towards an understanding of algorithmic structures on Facebook. Cyberpsychology, 8(3). Retrieved from http://www.cyberpsychology.eu/view.php?cisloclanku=2014093001\&article=2

Beunza, D., \& Millo, Y. (2014). Blended automation: Integrating algorithms on the floor of the New York stock exchange. Systemic Risk Centre. Retrieved from http://www.systemicrisk.ac.uk/publications/discussion-papers/blended-automationintegrating-algorithms-floor-new-york-stock

Boellstorff, T. (2013). Making big data, in theory. First Monday, 18(10). http://doi.org/10.5210/fm.v18i10.4869

Bolin, G., \& Schwarz, J. A. (2015). Heuristics of the algorithm: Big Data, user interpretation and institutional translation. Big Data \& Society, 2(2), 2053951715608406.

http://doi.org/10.1177/2053951715608406 
boyd, danah, \& Crawford, K. (2012). Critical questions for Big Data. Information, Communication \& Society, 15(5), 662-679. http://doi.org/10.1080/1369118X.2012.678878

boyd, danah, Levy, K., \& Marwick, A. (2014). The networked nature of algorithmic discrimination. Open Technology Institute. Retrieved from http://www.danah.org/papers/2014/DataDiscrimination.pdf

Bozdag, E. (2013). Bias in algorithmic filtering and personalization. Ethics and Information Technology, 15(3), 209-227. http://doi.org/10.1007/s10676-013-9321-6

Braverman, I. (2014). Governing the wild: Databases, algorithms, and population models as biopolitics (SSRN Scholarly Paper No. ID 2420199). Rochester, NY: Social Science Research Network. Retrieved from http://papers.ssrn.com/abstract $=2420199$

Brock, A. (2015). Deeper data: a response to boyd and Crawford. Media, Culture \& Society, 37(7), 10841088. http://doi.org/10.1177/0163443715594105

Bucher, T. (2012). Want to be on the top? Algorithmic power and the threat of invisibility on Facebook. New Media \& Society, 1461444812440159. http://doi.org/10.1177/1461444812440159

Burrell, J. (2015). How the machine "thinks:" Understanding opacity in machine learning algorithms (SSRN Scholarly Paper No. ID 2660674). Rochester, NY: Social Science Research Network. Retrieved from http://papers.ssrn.com/abstract=2660674

Carah, N. (2015). Algorithmic brands: A decade of brand experiments with mobile and social media. New Media \& Society, 1461444815605463. http://doi.org/10.1177/1461444815605463

Cardon, D. (2013). Dans l'esprit du PageRank. Réseaux, $n^{\circ} 177(1), 63-95$.

Cardoso Llach, D. (2015). Builders of the vision: Software and the imagination of design. London: Routledge.

Carr, N. (2014a). The glass cage: How our computers are changing us. New York, NY: W. W. Norton \& Company.

Carr, N. (2014b, April 16). The limits of social engineering: Review of social physics by Alex Pentland. MIT Technology Review. Retrieved from http://www.technologyreview.com/review/526561/thelimits-of-social-engineering/

Chan, A. (2015). Big data interfaces and the problem of inclusion. Media, Culture \& Society, 37(7), 10781083. http://doi.org/10.1177/0163443715594106

Cheney-Lippold, J. (2011). A new algorithmic identity soft biopolitics and the modulation of control. Theory, Culture \& Society, 28(6), 164-181. http://doi.org/10.1177/0263276411424420

Citron, D. K., \& Pasquale, F. A. (2014). The scored society: Due process for automated predictions (SSRN Scholarly Paper No. ID 2376209). Rochester, NY: Social Science Research Network. Retrieved from http://papers.ssrn.com/abstract=2376209

Columbia, D. (2009). The cultural logic of computation. Cambridge, MA: Harvard University Press.

Cormen, T. H. (2013). Algorithms unlocked. Cambridge, MA: MIT Press.

Crampton, J. W., Graham, M., Poorthuis, A., Shelton, T., Stephens, M., Wilson, M. W., \& Zook, M. (2013). Beyond the geotag: Situating "big data" and leveraging the potential of the geoweb. Cartography and Geographic Information Science, 40(2), 130-139. http://doi.org/10.1080/15230406.2013.777137

Crampton, J. W., Roberts, S. M., \& Poorthuis, A. (2014). The new political economy of geographical intelligence. Annals of the Association of American Geographers, 104(1), 196-214. http://doi.org/10.1080/00045608.2013.843436

Crawford, K. (2015). Can an algorithm be agonistic? Ten scenes from life in calculated publics. Science, Technology \& Human Values, 0162243915589635. http://doi.org/10.1177/0162243915589635

Crawford, K., Gray, M. L., \& Miltner, K. (2014). Critiquing big data: politics, ethics, epistemology. International Journal of Communication; Vol 8 (2014). Retrieved from http://ijoc.org/index.php/ijoc/article/view/2167/1164 
Crawford, K., \& Schultz, J. (2014). Big data and due process: Toward a framework to redress predictive privacy harms. Boston College Law Review, 55(1). Retrieved from http://bclawreview.org/review/55_1/03_crawford_schultz/

Crosman, P. (2015, October 19). Tracking bank customers online: Necessary, stalkerish, or both? Retrieved November 4, 2015, from http://www.americanbanker.com/news/banktechnology/tracking-bank-customers-online-necessary-stalkerish-or-both-1077310-1.html

Cukier, K. (2014, April 20). The backlash against big data. The Economist. Retrieved from http://www.economist.com/blogs/economist-explains/2014/04/economist-explains-10

Dalton, C. M. (2013). Sovereigns, spooks, and hackers: An early history of Google geo services and map mashups. Cartographica, 48(4), 261-274.

Dalton, C., \& Thatcher, J. (2014a). Inflated granularity: The promise of Big Data and the need for a critical data studies. Presented at the Association of American Geographers, Tampa, Florida. Retrieved from http://meridian.aag.org/callforpapers/program/AbstractDetail.cfm?AbstractID $=56048$

Dalton, C., \& Thatcher, J. (2014b). What does a critical data studies look like, and why do we care? Seven points for a critical approach to "big data." Retrieved from http://societyandspace.com/material/commentaries/craig-dalton-and-jim-thatcher-what-doesa-critical-data-studies-look-like-and-why-do-we-care-seven-points-for-a-critical-approach-to-bigdata/

Data \& Society Research Institute. (2014). Workshop primer: Algorithmic accountability. Retrieved from http://www.datasociety.net/pubs/2014-0317/AlgorithmicAccountabilityPrimer.pdf

Deleuze, G. (1992). Postscript on the societies of control. October, 59, 3-7.

Devendorf, L., \& Goodman, E. (2014). The algorithm multiple, the algorithm material. Presented at the Contours of Algorithmic Life, UC Davis. Retrieved from http://www.slideshare.net/egoodman/the-algorithm-multiple-the-algorithm-materialreconstructing-creative-practice

Diakopoulos, N. (2013a). Algorithmic accountability reporting: On the investigation of black boxes. Tow Center for Digital Journalism. Retrieved from http://towcenter.org/algorithmic-accountability-2/

Diakopoulos, N. (2013b, August 2). Sex, violence, and autocomplete algorithms. Slate. Retrieved from http://www.slate.com/articles/technology/future_tense/2013/08/words_banned_from_bing_a nd_google_s_autocomplete_algorithms.html

Diakopoulos, N. (2013c, October 3). Rage against the algorithms. The Atlantic. Retrieved from http://www.theatlantic.com/technology/archive/2013/10/rage-against-the-algorithms/280255/

Diakopoulos, N. (2015). Algorithmic accountability. Digital Journalism, 3(3), 398-415. http://doi.org/10.1080/21670811.2014.976411

Dietvorst, B. J., Simmons, J. P., \& Massey, C. (2014). Algorithm aversion: People erroneously avoid algorithms after seeing them err (SSRN Scholarly Paper No. ID 2466040). Rochester, NY: Social Science Research Network. Retrieved from http://papers.ssrn.com/abstract $=2466040$

Domingos, P. (2015). The master algorithm: How the quest for the ultimate learning machine will remake our world. New York, NY: Basic Books.

Dormehl, L. (2014). The Formula: How Algorithms Solve All Our Problems... and Create More. New York, NY: Perigee Books.

Dwork, C., Hardt, M., Pitassi, T., Reingold, O., \& Zemel, R. (2011). Fairness through awareness. arXiv:1104.3913 [cs]. Retrieved from http://arxiv.org/abs/1104.3913

Edelman, B. G., \& Luca, M. (2014). Digital discrimination: The case of Airbnb.com (SSRN Scholarly Paper No. ID 2377353). Rochester, NY: Social Science Research Network. Retrieved from http://papers.ssrn.com/abstract $=2377353$ 
Ekbia, H., Mattioli, M., Kouper, I., Arave, G., Ghazinejad, A., Bowman, T., ... Sugimoto, C. R. (2015). Big data, bigger dilemmas: A critical review. Journal of the Association for Information Science and Technology, 66(8), 1523-1545. http://doi.org/10.1002/asi.23294

Ekbia, H., \& Nardi, B. (2014). Heteromation and its (dis)contents: The invisible division of labor between humans and machines. First Monday, 19(6). Retrieved from http://firstmonday.org/ojs/index.php/fm/article/view/5331

Ensmenger, N. (2012). Is chess the drosophila of artificial intelligence? A social history of an algorithm. Social Studies of Science, 42(1), 5-30. http://doi.org/10.1177/0306312711424596

Feenberg, A. (2002). Transforming technology. New York, NY: Oxford University Press.

Fenwick, M. (2010). Ends and ways: The algorithmic politics of network neutrality. Global Media Journal : Canadian Edition.

Fuller, M., \& Goffey, A. (2012). Algorithms. Cambridge, MA: MIT Press.

Galliers, B., Newell, S., \& Graeme, S. (Eds.). (2016). Special Issue: The challenges and opportunities of "datification" Strategic impacts of "big" (and 'small') and real time data - for society and for organizational decision makers - The Journal of Strategic Information Systems. Elsevier. Retrieved from http://www.journals.elsevier.com/the-journal-of-strategic-informationsystems/call-for-papers/special-issue-datification/

Galloway, A. R. (2006). Gaming: Essays on algorithmic culture. Minneapolis: University Of Minnesota Press.

Gehl, R. W. (2014). Reverse engineering social media: Software, culture, and political economy in new media capitalism. Philadephia, PA: Temple University Press.

Geiger, R. S. (2011). The lives of bots. In Wikipedia: A Critical Point of View. Amsterdam: Institute of Network Cultures.

Geiger, R. S. (2014). Bots, bespoke, code and the materiality of software platforms. Information, Communication \& Society, 17(3), 342-356. http://doi.org/10.1080/1369118X.2013.873069

Gillespie, T. (2012a). Can an algorithm be wrong? Limn, 1(2). Retrieved from http://escholarship.org/uc/item/0jk9k4hj

Gillespie, T. (2012b, November 26). The relevance of algorithms. Retrieved from http://culturedigitally.org/2012/11/the-relevance-of-algorithms/

Gillespie, T. (2014, June 25). Algorithm: Digital keywords. Retrieved from http://culturedigitally.org/2014/06/algorithm-draft-digitalkeyword/

Gitelman, L. (2013). "Raw Data" Is an oxymoron. Cambridge, MA: MIT Press.

Goodchild, M. F. (2013). The quality of big (geo)data. Dialogues in Human Geography, 3(3), 280-284. http://doi.org/10.1177/2043820613513392

Graham, M. (2014, April 4). My response to the geoweb and "big data" alt.conference at \#AAG2014. Retrieved from http://www.zerogeography.net/2014/04/my-response-to-geoweb-and-bigdata.html

Graham, S. D. N. (2005). Software-sorted geographies. Progress in Human Geography, 29(5), 562-580. http://doi.org/10.1191/0309132505ph568oa

Graham, S., \& Wood, D. (2003). Digitizing surveillance: Categorization, space, inequality. Critical Social Policy, 23(2), 227-248. http://doi.org/10.1177/0261018303023002006

Granka, L. A. (2010). The politics of search: A decade retrospective. The Information Society, 26(5), 364374. http://doi.org/10.1080/01972243.2010.511560

Greenfield, A. (2015, June 29). Uber, or: The technics and politics of socially corrosive mobility. Retrieved from https://speedbird.wordpress.com/2015/06/29/uber-or-the-technics-and-politics-ofsocially-corrosive-mobility/

Grimmelmann, J. (2008). The Google dilemma (SSRN Scholarly Paper No. ID 1160320). Rochester, NY: Social Science Research Network. Retrieved from http://papers.ssrn.com/abstract $=1160320$ 
Grosser, B. (2014). What do metrics want? How quantification prescribes social interaction on Facebook: computational culture. Retrieved from http://computationalculture.net/article/what-dometrics-want

Gurevich, Y. (2011, June). What is an algorithm? Retrieved November 13, 2015, from http://research.microsoft.com/pubs/155608/209-3.pdf\#page=1\&zoom=auto,-44,792

Hahmann, S., \& Burghardt, D. (2013). How much information is geospatially referenced? Networks and cognition. International Journal of Geographical Information Science, 27(6), 1171-1189. http://doi.org/10.1080/13658816.2012.743664

Haklay, M. (2013). Neogeography and the delusion of democratization. Environment and Planning A, 45(1), 55-69.

Haklay, M., \& Weber, P. (2008). OpenStreetMap: User-Generated street maps. IEEE Pervasive Computing, 7(4), 12-18. http://doi.org/10.1109/MPRV.2008.80

Halevi, G. (Ed.). (2012). Special issue on big data. Research Trends, (30). Retrieved from http://www.researchtrends.com/wp-content/uploads/2012/09/Research_Trends_Issue30.pdf

Hallinan, B., \& Striphas, T. (2014). Recommended for you: The Netflix Prize and the production of algorithmic culture. New Media \& Society, 1461444814538646. http://doi.org/10.1177/1461444814538646

Hamilton, K., Karahalios, K., Sandvig, C., \& Eslami, M. (2014). A path to understanding the effects of algorithm awareness. In CHI'14 Extended Abstracts on Human Factors in Computing Systems (pp. 631-642). New York, NY, USA: ACM. http://doi.org/10.1145/2559206.2578883

Hannak, A., Mislove, A., Soeller, G., Wilson, C., \& Lazer, D. (2014). Measuring price discrimination and steering on e-commerce web sites. Presented at the Internet Measurement Conference.

Retrieved from http://www.ccs.neu.edu/home/cbw/pdf/imc151-hannak.pdf

Haraway, D. (1991). Simians, cyborgs, and women: The reinvention of nature. New York: Routledge. Harford, T. (2014, March 28). Big data: Are we making a big mistake? Financial Times. Retrieved from http://www.ft.com/intl/cms/s/2/21a6e7d8-b479-11e3-a09a-00144feabdc0.html\#axzz2ysdIXgD2

Harman, G. (2010). Technology, objects and things in heidegger. Cambridge Journal of Economics, 34(1).

Harris, L. M., \& Hazen, H. D. (2006). Power of maps: (Counter) mapping for conservation | Aboriginal mapping network website. An International E-Journal for Critical Geographies, 4(1). Retrieved from http://nativemaps.org/node/1892

Hazan, J. (2013). Stop being evil: A proposal for unbiased google search. Michigan Law Review, 111(5), 789-820.

Helmond, A. (2013). The algorithmization of the hyperlink. Retrieved from http://computationalculture.net/article/the-algorithmization-of-the-hyperlink

Helmreich, S. (1998). Recombination, rationality, reductionism and romantic reactions: culture, computers, and the genetic algorithm. Social Studies of Science, 28(1), 39-71. http://doi.org/10.1177/030631298028001002

Hess, A. (2014). You are what you compute (and what is computed for you): Considerations of digital rhetorical identification. Journal of Contemporary Rhetoric, 4(1/2), 1-18.

Hidalgo, C. A. (2014, April 29). Saving big data from big mouths [Scientific American]. Retrieved November 10, 2015, from http://www.scientificamerican.com/article/saving-big-data-from-bigmouths/

Hooker, J. N. (1994). Needed: An empirical science of algorithms. Operations Research, 42(2), 201-212.

Humphreys, L., Gill, P., \& Krishnamurthy, B. (2014). Twitter: A content analysis of personal information. Information, Communication \& Society, 17(7), 843-857. http://doi.org/10.1080/1369118X.2013.848917

Introna, L. D. (2011). The enframing of code agency, originality and the plagiarist. Theory, Culture \& Society, 28(6), 113-141. http://doi.org/10.1177/0263276411418131 
Introna, L. D. (2015). Algorithms, governance, and governmentality on governing academic writing. Science, Technology \& Human Values, 0162243915587360. http://doi.org/10.1177/0162243915587360

Introna, L., \& Nissenbaum, H. (2000). Shaping the web: Why the politics of search engines matters. The Information Society, 16(3), 169-185. http://doi.org/10.1080/01972240050133634

Introna, L., \& Wood, D. (2002). Picturing algorithmic surveillance: The politics of facial recognition systems. Surveillance \& Society, 2(2/3). Retrieved from http://library.queensu.ca/ojs/index.php/surveillance-and-society/article/view/3373

Japec, L., Kreuter, F., Berg, M., Biemer, P., Decker, P., Lampe, C., ... Usher, A. (2015). AAPOR report on big data (pp. 1-49). Hollywood, FL: Task Force.

Jurgenson, N. (2014, October 9). View From nowhere. The New Inquiry. Retrieved from http://thenewinquiry.com/essays/view-from-nowhere/

Kaplan, F. (2014). Linguistic capitalism and algorithmic mediation. Representations, 127(1), 57-63. http://doi.org/10.1525/rep.2014.127.1.57

Karppi, T., \& Crawford, K. (2015). Social media, financial algorithms and the hack crash. Theory, Culture \& Society, 0263276415583139. http://doi.org/10.1177/0263276415583139

Kitchin, R. (2014a). Thinking critically about and researching algorithms (SSRN Scholarly Paper No. ID 2515786). Rochester, NY: Social Science Research Network. Retrieved from http://papers.ssrn.com/abstract $=2515786$

Kitchin, R. (2014b, April 16). Short presentation on the need for critical data studies. Retrieved from http://www.maynoothuniversity.ie/progcity/2014/04/short-presentation-on-the-need-forcritical-data-studies/

Kitchin, R., \& Dodge, M. (2011). Code/space: Software and everyday life. Cambridge, MA: MIT Press.

Kitchin, R., \& Lauriault, T. P. (2014). Small data, data infrastructures and big data (SSRN Scholarly Paper No. ID 2376148). Rochester, NY: Social Science Research Network. Retrieved from http://papers.ssrn.com/abstract $=2376148$

Kockelman, P. (2013). The anthropology of an equation. Sieves, spam filters, agentive algorithms, and ontologies of transformation. HAU: Journal of Ethnographic Theory, 3(3), 33-61. http://doi.org/10.14318/hau3.3.003

Kockelman, P. (2014). Linguistic anthropology in the age of language automata. In The Cambridge Handbook of Linguistic Anthropology. Cambridge University Press. Retrieved from http://dx.doi.org/10.1017/СВ09781139342872.034

Kowalski, R. (1979). Algorithm = Logic + Control. Commun. ACM, 22(7), 424-436. http://doi.org/10.1145/359131.359136

Kraemer, F., Overveld, K. van, \& Peterson, M. (2010). Is there an ethics of algorithms? Ethics and Information Technology, 13(3), 251-260. http://doi.org/10.1007/s10676-010-9233-7

Kushner, S. (2013). The freelance translation machine: Algorithmic culture and the invisible industry. New Media \& Society, 15(8), 1241-1258. http://doi.org/10.1177/1461444812469597

Lee, M. K., Kusbit, D., Metsky, E., \& Dabbish, L. (2015). Working with machines: The impact of algorithmic and data-driven management on human workers. In Proceedings of the 33rd Annual ACM Conference on Human Factors in Computing Systems (pp. 1603-1612). New York, NY, USA: ACM. http://doi.org/10.1145/2702123.2702548

Lenglet, M. (2011). Conflicting codes and codings how algorithmic trading is reshaping financial regulation. Theory, Culture \& Society, 28(6), 44-66. http://doi.org/10.1177/0263276411417444

Lenglet, M. (2013). Algorithms and the manufacture of financial reality. In Objects and materials. London: Routledge. Retrieved from http://www.academia.edu/5575392/Algorithms_and_the_Manufacture_of_Financial_Reality 
Leyshon, A., French, S., Thrift, N., Crewe, L., \& Webb, P. (2005). Accounting for e-commerce: Abstractions, virtualism and the cultural circuit of capital. Economy and Society, 34(3), 428-450. http://doi.org/10.1080/03085140500112160

MacCormick, J. (2012). Nine Algorithms That Changed the Future: The Ingenious Ideas That Drive Today's Computers. Princeton, NJ: Princeton University Press.

Mackenzie, A. (2013). Programming subjects in the regime of anticipation: Software studies and subjectivity. Subjectivity, 6(4), 391-405. http://doi.org/10.1057/sub.2013.12

Mackenzie, A. (2015). The production of prediction: What does machine learning want? European Journal of Cultural Studies, 18(4-5), 429-445. http://doi.org/10.1177/1367549415577384

MacKenzie, D. (2006). An engine, not a camera: How financial models shape markets. Cambridge, MA: MIT Press.

MacKenzie, D. (2014, February). A sociology of algorithms: High frequency trading and the shaping of markets. Retrieved from http://www.sps.ed.ac.uk/_data/assets/pdf_file/0004/156298/Algorithms25.pdf

Mager, A. (2012). Algorithmic ideology. Information, Communication \& Society, 15(5), 769-787. http://doi.org/10.1080/1369118X.2012.676056

Mahnke, M., \& Uprichard, E. (2014). Algorithming the algorithm. In Society of the query reader: Reflections on web search. Amsterdam: Institute of Network Cultures. Retrieved from http://networkcultures.org/query/wpcontent/uploads/sites/4/2014/06/19.Mahnke_Uprichard.pdf

Manovich, L. (2013). Software takes command. New York: Bloomsbury Academic.

Markus, M. L., \& Topi, H. (2015). Big data workshop final report. Bentley University. Retrieved from https://www.bentley.edu/files/2015/10/08/BigDataWorkshopFinalReport.pdf

Marres, N. (2012). The redistribution of methods: On intervention in digital social research, broadly conceived. The Sociological Review, 60, 139-165. http://doi.org/10.1111/j.1467954X.2012.02121.x

Mayer-Schoernberger, V., \& Kenneth, C. (2013). Big Data: A revolution that will transform how we live, work, and think. New York, NY: Houghton Mifflin Harcourt.

McKelvey, F. R. (2014). Algorithmic media need algorithmic methods: Why publics matter. Canadian Journal of Communication, 39(4). Retrieved from http://www.cjconline.ca/index.php/journal/article/view/2746

McQuillan, D. (2015). Algorithmic states of exception. European Journal of Cultural Studies, 18(4/5). Retrieved from http://ecs.sagepub.com/

Medina, E. (2015). Rethinking algorithmic regulation. Kybernetes, 44(6/7), 1005-1019. http://doi.org/10.1108/K-02-2015-0052

Metcalf, J. (2014). Taxonomy of NSF's "Big Data" research projects. Research Institute. Retrieved from http://bdes.datasociety.net/council-output/taxonomy-of-nsfs-big-data-research-projects/

Miyazaki, S. (2012). Algorhythmics: Understanding micro-temporality in computational cultures. Computational Cultures. Retrieved from http://computationalculture.net/article/algorhythmicsunderstanding-micro-temporality-in-computational-cultures

Moschovakis, Y. N. (2000). What is an algorithm? In B. Engquist \& W. Schmid (Eds.), Mathematics unlimited - 2001 and beyond. Berlin: Springer-Verlag.

Muniesa, F. (2014). Discovering stock prices. In The provoked economy: Economic reality and the performative turn. London: Routledge. Retrieved from http://bit.ly/provokedeconomy

Napoli, P. M. (2014). On automation in media industries: Integrating algorithmic media production into media industries scholarship. Media Industries, 1(1). Retrieved from http://www.mediaindustriesjournal.org/index.php/mij/article/view/14 
Neyland, D. (2007). Achieving transparency: The visible, invisible and divisible in academic accountability networks. Organization, 14(4), 499-516. http://doi.org/10.1177/1350508407078050

Neyland, D. (2015a). Bearing account-able witness to the ethical algorithmic system. Science, Technology \& Human Values, 0162243915598056. http://doi.org/10.1177/0162243915598056

Neyland, D. (2015b). On organizing algorithms. Theory, Culture \& Society, 32(1), 119-132. http://doi.org/10.1177/0263276414530477

Noble, S. U. (2012, March 8). Missed connections: what search engines say about women. Bitch Magazine, (54). Retrieved from http://safiyaunoble.com/2012/03/08/bitch-magazine-article/

O'Reilly, T. (2013). Open data and algorithmic regulation. In B. Goldstein \& L. Dyson (Eds.), Beyond transparency: Open data and the future of civic innovation. San Francisco, CA: Code for America Press. Retrieved from http://beyondtransparency.org/chapters/part-5/open-data-andalgorithmic-regulation/

Papacharissi, Z. (2015). The unbearable lightness of information and the impossible gravitas of knowledge: Big Data and the makings of a digital orality. Media, Culture \& Society, 37(7), 10951100. http://doi.org/10.1177/0163443715594103

Pariser, E. (2013). The filter bubble: How the new personalized web is changing what we read and how we think. New York, NY: Penguin Books.

Pasquale, F. (2006). Rankings, reductionism, and responsibility. Cleveland State Law Review, 54(115). Retrieved from http://digitalcommons.law.umaryland.edu/fac_pubs/1351

Pasquale, F. (2015a). The algorithmic self. The Hedgehog Review, 17(1). Retrieved from http://www.iascculture.org/THR/THR_article_2015_Spring_Pasquale.php

Pasquale, F. (2015b). The black box society: The secret algorithms that control money and information. Cambridge, MA: Harvard University.

Pasquinelli, M. (2014, March 12). Google's PageRank Algorithm: a diagram of cognitive capitalism and the rentier of the common intellect. Retrieved from http://matteopasquinelli.com/googlepagerank-algorithm/

Pavlovskaya, M. (2006). Theorizing with GIS: A tool for critical geographies? Environment and Planning A, 38(11), 2003-2020. http://doi.org/10.1068/a37326

Pearce, R. (2013, May 28). Big data is BS: Obama campaign CTO. CIO. Retrieved from http://www.cio.com.au/article/462961/big_data_bs_obama_campaign_cto/

Poon, M. (2007). Scorecards as devices for consumer credit: The case of Fair, Isaac \& Company Incorporated. The Sociological Review, 55, 284-306. http://doi.org/10.1111/j.1467954X.2007.00740.x

Punathambekar, A., \& Kavada, A. (2015). Debating big data. Media, Culture \& Society, 37(7), 1076-1077. http://doi.org/10.1177/0163443715594870

Qiu, J. L. (2015). Reflections on Big Data: "Just because it is accessible does not make it ethical." Media, Culture \& Society, 37(7), 1089-1094. http://doi.org/10.1177/0163443715594104

Ratto, M. (2011). Critical making: Conceptual and material studies in technology and social life. The Information Society, 27(4), 252-260. http://doi.org/10.1080/01972243.2011.583819

Reigeluth, T. B. (2014). Why data is not enough: Digital traces as control of self and self-control. Surveillance \& Society, 12(2), 243-254.

Rieder, B. (2012, September 28). What is in pagerank? A historical and conceptual investigation of a recursive status index.: computational culture. Retrieved from http://computationalculture.net/article/what_is_in_pagerank

Rieder, B., \& Sire, G. (2014). Conflicts of interest and incentives to bias: A microeconomic critique of Google's tangled position on the Web. New Media \& Society, 16(2), 195-211. http://doi.org/10.1177/1461444813481195 
Rijmenam, M. van. (2015, April 15). The Los Angeles Police Department Is predicting and Ffghting crime with big data. DataFloq. Retrieved from https://datafloq.com/read/los-angeles-policedepartment-predicts-fights-crim/279

Roberge, J., \& Melançon, L. (2015). Being the King Kong of algorithmic culture is a tough job after all Google's regimes of justification and the meanings of Glass. Convergence: The International Journal of Research into New Media Technologies, 1354856515592506. http://doi.org/10.1177/1354856515592506

Rouvroy, A., \& Berns, T. (2013). Gouvernementalité algorithmique et perspectives d'émancipation. Réseaux, $n^{\circ} 177(1), 163-196$.

Ryan, L. (2014, September 15). Feds Investigate "Discrimination by Algorithm." National Journal. Retrieved from http://www.nationaljournal.com/tech/2014/09/15/feds-investigatediscrimination-algorithm

Sadowski, J. (2015, April 28). From mega-machines to mega-algorithms. The New Inquiry. Retrieved from http://thenewinquiry.com/essays/from-mega-machines-to-mega-algorithms/

Sandvig, C. (2015). Seeing the sort: The aesthetic and industrial defense of "the algorithm." Journal of the New Media Caucus. Retrieved from http://median.newmediacaucus.org/art-infrastructuresinformation/seeing-the-sort-the-aesthetic-and-industrial-defense-of-the-algorithm/

Sandvig, C., Hamilton, K., Karahalios, K., \& Langhort, C. (2014a). An algorithm audit. In Data and discrimination: Collected essays. Washington D.C.: New America Foundation. Retrieved from http://www-personal.umich.edu/ csandvig/research/An\%20Algorithm\%20Audit.pdf

Sandvig, C., Hamilton, K., Karahalios, K., \& Langhort, C. (2014b). Auditing Algorithms: Research Methods for Detecting Discrimination on Internet Platforms. In Auditing Algorithms From the Outside: Seattle, WA. Retrieved from http://wwwpersonal.umich.edu/ csandvig/research/Auditing\%20Algorithms\%20-\%20Sandvig\%20\%20ICA\%202014\%20Data\%20and\%20Discrimination\%20Preconference.pdf

Scannell, J. (2015). What can an algorithm do? DIS Magazine. Retrieved from http://dismagazine.com/discussion/72975/josh-scannell-what-can-an-algorithm-do/

Schull, N. D. (2014). Addiction by design: Machine gambling in Las Vegas. Princeton, NJ: Princeton University Press.

Schuppli, S. (2014). Deadly algorithms. Radical Philosophy, 187, 1-8.

Seaver, N. (2013). Knowing algorithms. Presented at the MiT: Media in Transition 8, Cambridge, MA. Retrieved from http://static1.squarespace.com/static/55eb004ee4b0518639d59d9b/t/55ece1bfe4b030b2e830 2e1e/1441587647177/seaverMiT8.pdf

Seaver, N. (2015a). Bastard algebra. In T. Boellstorff \& B. Maurer (Eds.), Data: Now bigger and better!. Chicago, IL: Prickly Paradigm Press.

Seaver, N. (2015b). The nice thing about context is that everyone has it. Media, Culture \& Society, 37(7), 1101-1109. http://doi.org/10.1177/0163443715594102

Shah, V. (2013, August 28). Map of stop and frisks in New York City show concentration by race and neighborhood | Untapped Cities. Retrieved November 10, 2015, from http://untappedcities.com/2013/08/28/new-map-shows-police-stop-and-frisks-according-torace-and-neighbourhood-in-new-york-city/

Sieber, R. (2006). Public participation geographic information systems: A literature review and framework. Annals of the Association of American Geographers, 96(3), 491-507. http://doi.org/10.1111/j.1467-8306.2006.00702.x

Singer, N. (2015, June 4). Sharing data, but not happily. The New York Times. Retrieved from http://www.nytimes.com/2015/06/05/technology/consumers-conflicted-over-data-miningpolicies-report-finds.html 
Slavin, K. (2011). How algorithms shape our world. Retrieved from http://www.ted.com/talks/kevin_slavin_how_algorithms_shape_our_world

Snake-beings, E. (2013). From Ideology to Algorithm: the Opaque Politics of the Internet. Journal of Media and Culture, 23. Retrieved from http://connection.ebscohost.com/c/articles/97515688/from-ideology-algorithm-opaquepolitics-internet

Snider, L. (2014). Interrogating the algorithm: debt, derivatives and the social reconstruction of stock market trading. Critical Sociology, 40(5), 747-761. http://doi.org/10.1177/0896920513504603

Soderman, B. (2007). The Index and the Algorithm. Differences, 18(1), 153-186. http://doi.org/10.1215/10407391-2006-026

Steiner, C. (2013). Automate this: How algorithms took over our markets, our jobs, and the world. New York, NY: Portfolio.

Sterne, J. (2006). The mp3 as cultural artifact. New Media \& Society, 8(5), 825-842. http://doi.org/10.1177/1461444806067737

Striphas, T. (2015). Algorithmic culture. European Journal of Cultural Studies, 18(4-5), 395-412. http://doi.org/10.1177/1367549415577392

Thatcher, J. (2014). Big data, big questions | living on fumes: Digital footprints, data fumes, and the limitations of spatial big data. International Journal of Communication, 8(0), 19.

Thrift, N., \& French, S. (2002). The automatic production of space. Transactions of the Institute of British Geographers, 27(3), 309-335. http://doi.org/10.1111/1475-5661.00057

Totaro, P., \& Ninno, D. (2014). The concept of algorithm as an interpretative key of modern rationality. Theory, Culture \& Society, 31(4), 29-49. http://doi.org/10.1177/0263276413510051

Tsou, M.-H. (2014). Building a new research agenda for geographers: Human dynamics in the mobile age (hdma). Presented at the Association of American Geograhers, Tampa, Florida. Retrieved from http://meridian.aag.org/callforpapers/program/AbstractDetail.cfm?AbstractID $=55574$

Tufekci, Z. (2015). Algorithmic harms beyond facebook and google: Emergent challenges of computational agency. Colorado Technology Law Journal, 13, 203.

Turow, J., Hennessy, M., \& Draper, N. (2015). The tradeoff fallacy: How marketers are misrepresenting American consumers and opening them up to exploitation. University of Pennsyvnia. Retrieved from https://www.asc.upenn.edu/sites/default/files/TradeoffFallacy_1.pdf

Turow, J., McGuigan, L., \& Maris, E. R. (2015). Making data mining a natural part of life: Physical retailing, customer surveillance and the 21st century social imaginary. European Journal of Cultural Studies, 18(4-5), 464-478. http://doi.org/10.1177/1367549415577390

Upturn. (2014). Civil rights, big data, and our algorithmic future. Retrieved from https://bigdata.fairness.io/wp-content/uploads/2015/04/2015-04-20-Civil-Rights-Big-Data-andOur-Algorithmic-Future-v1.2.pdf

Uricchio, W. (2011). The algorithmic turn: Photosynth, augmented reality and the changing implications of the image. Visual Studies, 26(1), 25-35. http://doi.org/10.1080/1472586X.2011.548486

Vaidhyanathan, S. (2006). Afterword: Critical information studies. Cultural Studies, 20(2-3), 292-315. http://doi.org/10.1080/09502380500521091

Vaidhyanathan, S. (2012). The googlization of everything (and why we should worry). Berkeley, CA: UC Press.

Van Couvering, E. (2004). New media? The political economy of internet search engines. Presented at the Annual Conference of the International Association of Media \& Communications Researchers, Porto Alegre, Brazil. Retrieved from http://citeseerx.ist.psu.edu/viewdoc/summary?doi=10.1.1.129.1900 
Van Couvering, E. (2007). Is relevance relevant? Market, science, and war: discourses of search engine quality. Journal of Computer-Mediated Communication, 12(3), 866-887. http://doi.org/10.1111/j.1083-6101.2007.00354.x

Van Dijck, J. (2012). Facebook and the engineering of connectivity: A multi-layered approach to social media platforms. Convergence: The International Journal of Research into New Media Technologies, 1354856512457548. http://doi.org/10.1177/1354856512457548

Van Dijck, J. (2013). The culture of connectivity: A critical history of social media. Oxford: Oxford University Press.

Vis, F. (2013). A critical reflection on Big Data: Considering APIs, researchers and tools as data makers. First Monday, 18(10). Retrieved from http://firstmonday.org/ojs/index.php/fm/article/view/4878

Wainwright, J., \& Bryan, J. (2009). Cartography, territory, property: Postcolonial reflections on indigenous counter-mapping in Nicaragua and Belize. Special Issue: Indigenous Cartographies., 16(2), 153-178. http://doi.org/10.1177/1474474008101515

Wangsness, T., \& Franklin, J. (1966). "Algorithm" and "Formula." Commun. ACM, 9(4), 243-. http://doi.org/10.1145/365278.365286

Webmoor, T. (2014). Algorithmic alchemy, or the work of code in the age of computerized visualization. In Visualization in the Age of Computerization. New York, NY: Routledge.

Weltevrede, E., Helmond, A., \& Gerlitz, C. (2014). The politics of real-time: A device perspective on social media platforms and search engines. Theory, Culture \& Society, 31(6), 125-150. http://doi.org/10.1177/0263276414537318

Wihbey, J. (2015, January 14). The possibilities of digital discrimination: Research on e-commerce, algorithms and big data. Retrieved from http://journalistsresource.org/studies/society/internet/possibilities-online-racial-discriminationresearch-airbnb

Wilf, E. (2013). Toward an anthropology of computer-mediated, algorithmic forms of sociality. Current Anthropology, 54(6), 716-739. http://doi.org/10.1086/673321

Wilson, M. W. (2015). Morgan Freeman is dead and other big data stories. Cultural Geographies, 22(2), 345-349. http://doi.org/10.1177/1474474014525055

Wright, D. J., Goodchild, M. F., \& Proctor, J. D. (1997). Reply: Still hoping to turn that theoretical corner. Annals of the Association of American Geographers, 87(2), 373-373. http://doi.org/10.1111/0004-5608.00059

Yeager, C. D., \& Steiger, T. (2013). Applied geography in a digital age: The case for mixed methods. Applied Geography, 39, 1-4. http://doi.org/10.1016/j.apgeog.2012.12.001

Zarsky, T. (2015). The trouble with algorithmic decisions an analytic road map to examine efficiency and fairness in automated and opaque decision making. Science, Technology \& Human Values, 0162243915605575. http://doi.org/10.1177/0162243915605575

Ziewitz, M. (2012). Evaluation as governance: The practical politics of reviewing, rating and ranking on the web. Oxford: University of Oxford.

Ziewitz, M. (2015). Governing algorithms myth, mess, and methods. Science, Technology \& Human Values, 0162243915608948. http://doi.org/10.1177/0162243915608948

Zook, M., \& Poorthuis, A. (2014). Offline brews and online views: Exploring the geography of beer tweets. In M. Patterson \& N. Hoalst-Pullen (Eds.), The Geography of Beer (pp. 201-209). Springer Netherlands. Retrieved from http://link.springer.com/chapter/10.1007/978-94-007-7787-3_17 